\title{
Evaluation of stone durability using a combination of ultrasound, mechanical and accelerated aging tests
}

\author{
E Molina $^{1}$, G Cultrone ${ }^{1}$, E Sebastián ${ }^{1}$ and F J Alonso ${ }^{2}$ \\ ${ }^{1}$ Departamento de Mineralogía y Petrología, Facultad de Ciencias, Universidad de Granada, Spain \\ ${ }^{2}$ Departamento de Geología, Área de Petrología y Geoquímica, Universidad de Oviedo, Spain \\ E-mail: molinap@ugr.es
}

Received 4 February 2013

Accepted for publication 6 March 2013

Published 5 June 2013

Online at stacks.iop.org/JGE/10/035003

\begin{abstract}
The durability of a rock when exposed to decay agents is an important criterion when assessing its quality as a building material. Our study focuses on six varieties of natural stone (two limestones, one dolostone, one travertine and two sandstones) that are widely used in both new and historical buildings. In order to assess their quality, we measured and characterized their dynamic elastic properties using ultrasounds, we measured their compressive strength using the uniaxial compression test and we evaluated their durability by means of accelerated aging tests (freeze-thaw and salt crystallization). In order to get a full picture of the decay suffered by the different stones, we determined the composition and amount of the clay fraction of the six stones. We also observed small fragments subjected to the salt crystallization test under an environmental scanning electron microscope to study any textural change and measured the changes of colour on the surface with a spectrophotometer. Finally, we analysed the pore system of the stones before and after their deterioration using mercury injection porosimetry. We then compared the results for the different stones and found that dolostone obtained the best results, while the two limestones proved to be the least durable and had the lowest compressive strength.
\end{abstract}

Keywords: durability, sedimentary stone, ultrasound velocity, compressive strength, decay test, pore system

(Some figures may appear in colour only in the online journal)

\section{Introduction}

When doing prevention and conservation work on our architectural heritage, it is important to realize that the durability of the stones depends both on their intrinsic properties and on the decay factors in the environment. When we talk about the durability of a material we are referring to its resistance to alteration or decay, and its capacity to maintain the same size, shape, properties and aesthetic appearance over time (Bell 1993). The main objective of most research into building materials such as brick, mortar and stone is to assess their durability (Maage 1984, Lewry and Crewdson 1994, De Belie et al 2000a, 2000b, Delgado Rodrigues 2001, Cultrone et al 2005, Varas et al 2005, Peris Mora 2007). In the specific case of natural stone, the damage it suffers depends a great deal on its petrographic characteristics and on the particular decay agent acting on it (Richardson 1991). Given that natural stone is still an important material in modern-day construction (Fort 2008), the petrophysical study of the different building stones is of the utmost importance for correct, effective preservation and restoration work. To this end various studies have been made of sedimentary (sandstones, limestones, dolostones, etc) (Andriani and Walsh 2002, Angeli et al 2006), metamorphic (mainly marbles) (Siegesmund et al 2000, Luque et al 2010) and igneous rocks (granites, basalts, etc) (Herrera et al 2004, Fort et al 2010a) in order to assess their quality as building 
materials on the basis of their petrophysical characteristics, and in some of these papers the authors also proposed mathematical formulae to explain the behaviour of the rocks when exposed to alteration processes (Benavente et al 2004, Mutlutürl et al 2004, Yavuz et al 2006, Marini and Bellopede 2010).

There are many possible alteration factors and their interaction with the stones is complex due to the number of variables involved such as the position and orientation of the stones in the building, contact with other materials, the weather conditions and the intrinsic properties of each material (Rancan 2002, Cultrone et al 2007). The durability of the natural stone does not only depend on the alteration factors, it also depends on the mineralogy, the rock fabric and the pore system (Ordoñez et al 1997, King 2002, Török and Vásárhelyi 2010). Of these, the pore system has a particularly important role in the durability of rock, as it affects the movement of fluids inside the rock, thereby accelerating its physical, chemical and biological deterioration (Molina et al 2011). In addition, certain minerals can affect the durability of the rock more than others, especially those whose properties vary according to the environmental conditions. One of the greatest problems when it comes to assessing the durability of rocks, or even of terrains, lies in swellable-clay minerals in particular those from the smectites group. These clays may be found, albeit in low concentrations, in many of the sedimentary rocks currently used in the construction industry or used in the past in our historical buildings. Some of the decay seen on buildings is therefore caused by the action of these minerals (Sebastian et al 2008, Colas et al 2011, Anania et al 2012).

Various techniques are used in the characterization of building materials. The compactness of the stone is measured with ultrasounds. One advantage of this technique is that it is non-destructive, which means that the same sample material can be used in other tests. The wave velocity depends on the percentage of pores, the volume and the type of fissures, the mineralogical composition, the density and the moisture (Simmons 1965). The way the waves propagate inside the stone depends on the direction and the orientation and this provides a picture of the degree of anisotropy (Guydader and Denis 1986), which varies depending on the orientation of the components (grains, pores, etc), the rock fabric and its structure (Fort et al 2011). The presence and distribution of anisotropies will affect, at least partially, the durability of the stones (Fort et al 2010b).

Accelerated aging tests are particularly important in the study of stone building materials, because despite being destructive tests, in a relatively short space of time they enable researchers to estimate the level of damage suffered by the materials when exposed to decay agents in the laboratory (Steiger 2005, Espinosa et al 2008, Buj et al 2010, LudovicoMarques and Chastre, 2012). The results of these tests give us a better, more complete picture of how the different factors (ice, salts, air pollution, etc) affect the decay of the materials under real conditions (Laycock 2002, Grossi et al 2007). By measuring the compactness of stone using ultrasounds during the aging tests we can monitor the textural changes that take place in the stone (Martinez-Martinez et al 2011).

Similar to the aging tests, the mechanical tests are also destructive but provide essential information about the behaviour of the natural stone when a load is applied to it. The compressive strength of a rock is directly related to its rock fabric, and in particular to the pore system and the degree of cohesion between the grains. For this reason, the results for compressive strength and ultrasound coincide to a large extent with those measuring the decay that takes place during accelerated aging tests.

The aim of this paper is to establish the relationship between the durability of the six types of porous sedimentary rocks used in the building industry and their dynamic and mechanical properties. In order to characterize their properties we measured the velocity of propagation of ultrasounds, the degree of anisotropy and the resistance to uniaxial compression in intact quarried rock. We then subjected them to accelerated aging tests (freeze-thaw and salt crystallization) in order to determine their durability. During the tests we periodically monitored the degree of damage to the test samples using ultrasounds, and then we studied the changes that had taken place in the pore system and the possible depositing of salts in pores and fissures. To complete the analysis, we evaluated the textural and superficial changes and compared the differences in the pore system between intact and altered samples. For this purpose, we also characterized the mineralogy of the clay fraction to determine the amount of clay minerals present in our rocks as well their composition and how this might affect their durability.

\section{Materials used}

Six stones were selected for this study (two sandstones, two limestones, one dolostone and one travertine). These rocks are currently used as construction materials and most of them were also used in the past in historical buildings that form part of Spain's cultural heritage.

\subsection{Santa Pudia limestone}

Santa Pudia limestone (SP) is a Tortonian bioclastic calcarenite (figure 1(a)) from Escuzar (Granada) and is composed basically of calcitic bioclasts (foraminifera, red algae, echinoderms, bryozoans, bivalves and serpulids) and a small amount of siliceous fragment of about $0.5 \mathrm{~mm}$ in size (Rodriguez Navarro 1994). The rock fabric is clast-supported (the percentage of the fossil fragments is bigger than 95\%) with little cohesion, while the matrix is microsparitic and contains sporadic amounts of cement (Luque et al 2008). Porosity varies between $30 \%$ and 36\% (Rodriguez-Navarro 1994). Most of the larger pores are intergranular (over $0.8-1 \mathrm{~cm}$ ), while the smaller ones are the result of the intraclastic porosity associated with skeletal fragments (Urosevic 2011).

\subsection{Yellow gold travertine}

Yellow gold travertine (TA) from Albox (Almeria) is a Pleistocene travertine. It has alternating yellow and brown bands due to the presence of iron and manganese oxides/hydroxides (Garcia del Cura et al 2007). The yellow bands are characterized by macrocrystals of calcite, in some 


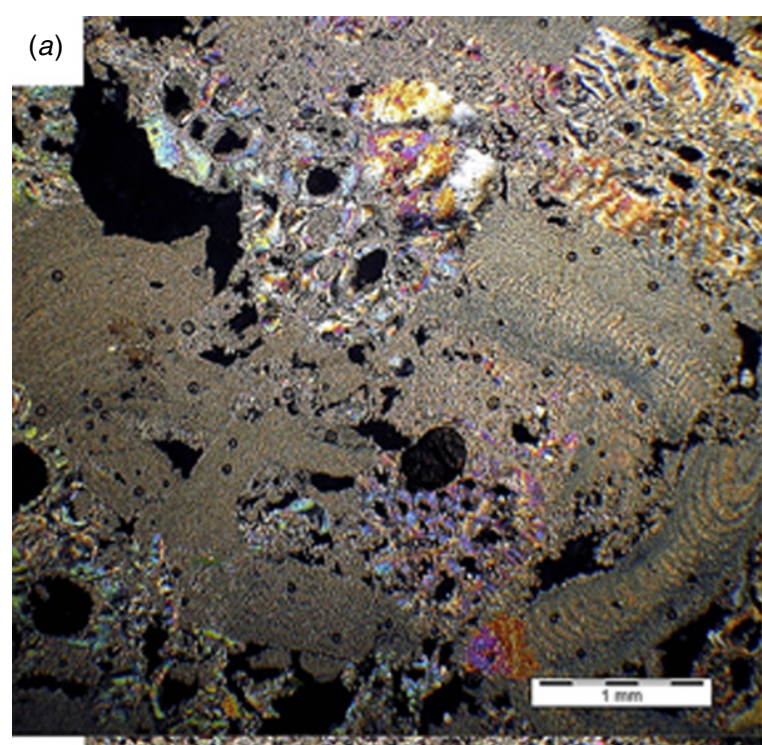

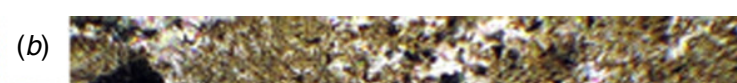

Molina et al

$(c)$

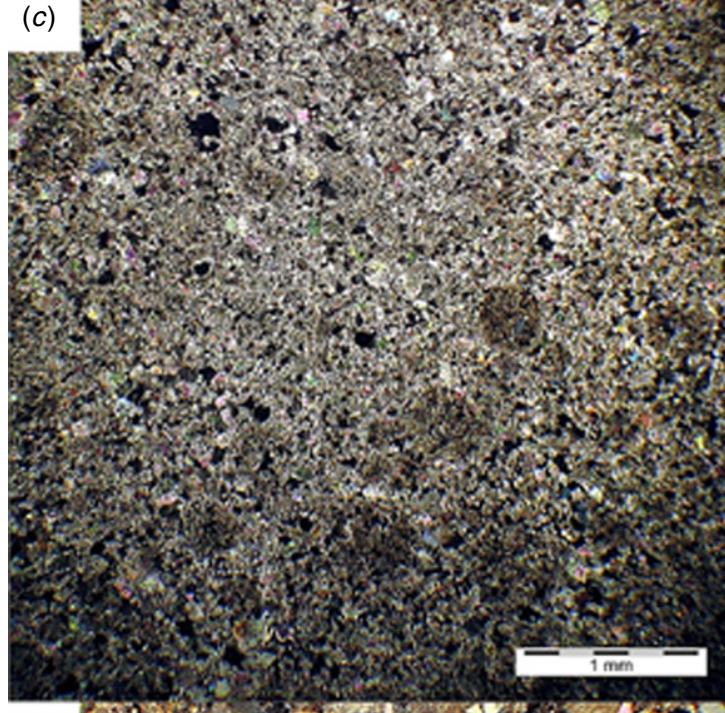

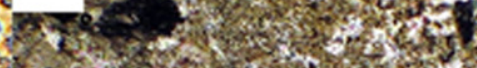

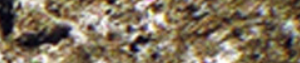

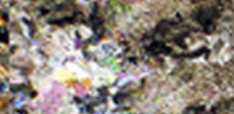

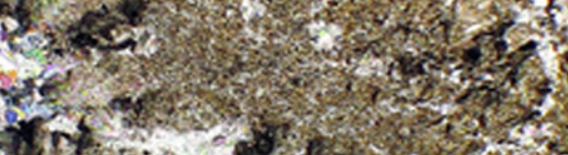

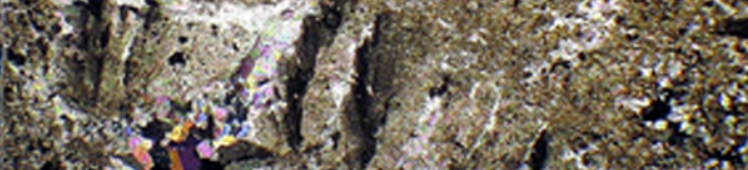

(x)

actires
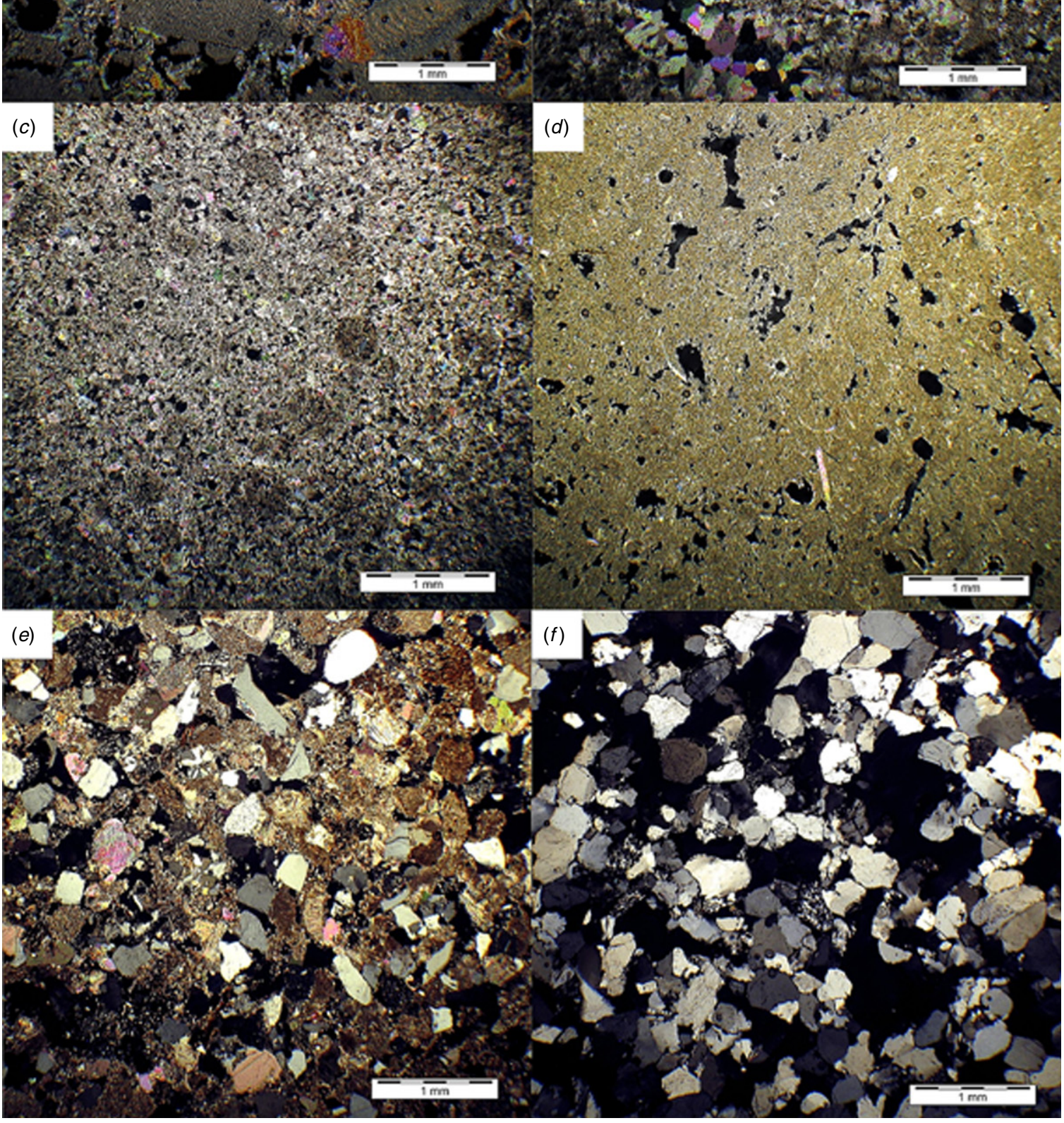

Figure 1. Polarized optical microscopy images showing the texture and mineralogy of Santa Pudia limestone (SP, $(a)$ ), Albox travertine (TA, $(b))$, Boñar dolostone (DB, $(c))$, Fraga limestone $(\mathrm{CF},(d))$, Uncastillo sandstone $(\mathrm{AU},(e))$ and Villaviciosa sandstone $(\mathrm{AV},(f))$. 
cases with fibrous morphology (figure $1(b)$ ). The pores are usually elongated in shape and they can be quite large (over $1-2 \mathrm{~cm}$ ). Brown bands are composed of calcitic microcrystals and the pores are normally rounded and small in size (Molina et al 2011).

\subsection{Boñar dolostone}

Boñar dolostone (DB) is quarried in Boñar (Leon) and dates back to the Upper Cretaceous Age. It has a crystalline rock fabric due to the dolomitization of the original limestone, a process during which the calcite is replaced with dolomite crystals with an approximate size of $30 \mu \mathrm{m}$ (Gomez-Fernandez et al 2003). Intergranular pores are more abundant than intragranular ones (figure $1(c)$ ), and all the pores measured less than $100 \mu \mathrm{m}$ (Molina et al 2011).

\subsection{Fraga limestone}

Fraga limestone (CF) is quarried in Fraga (Huesca) and sold under the trade name 'Campanil Limestone'. It is a grey micritic lacustrine limestone (Lower Miocene), composed of fossil fragments (charophytes algae, bivalves and foraminifera), with a matrix-supported rock fabric (figure $1(d)$ ) and can be classified as bioclastic wackstone (Dunham 1962). Buj-Fandos (2008) indicated that small amounts (around $1.1 \%$ ) of quartz grains and organic matter can also be identified and that the pores are abundant, irregular in shape and small (below $100 \mu \mathrm{m}$ ).

\subsection{Uncastillo sandstone}

Uncastillo sandstone (AU) comes from the town of the same name. According to Buj and Gisbert (2007) this rock can be classified as a Lower Miocene litharenite. It has similar proportions of carbonatic and siliceous fragments. Metamorphic rock fragments have been also detected. Stone fragments are sub-angular to round in shape and generally range between 0.25 and $0.35 \mathrm{~mm}$ in size (figure $1(e)$ ). The pores are disposed between the calcite and quartz grains and measure less than $100 \mu \mathrm{m}$ (Buj-Fandos 2008).

\subsection{Villaviciosa sandstone}

Villaviciosa sandstone (AV) is quarried in Quintueles (Asturias) and is Upper Jurassic grey sandstone. It is sold under the trade name of 'La Marina Sandstone'. It is composed entirely of clasts of quartz and some fragments of feldspar with quartz overgrowth cement. It has a grain-supported rock fabric and the grain size ranges between 0.25 and $0.4 \mathrm{~mm}$ (Suarez del Rio et al 2002). The porosity is interclastic and pore size ranges between 50 and $200 \mu \mathrm{m}$ (figure $1(f)$ ), occasionally reaching as high as $700 \mu \mathrm{m}$ (Molina et al 2011).

\section{Experimental methods}

The pore system and the pore size distribution of the stones were evaluated using a Micromeritics Autopore III model 9410 mercury intrusion porosimeter (MIP). The effective range of measurement varies between 0.003 and $360 \mu \mathrm{m}$, and a maximum pressure of $414 \mathrm{Mpa}$ was exerted. Samples of about $1 \mathrm{~cm}^{3}$ were used, after being dried in a convection oven for $24 \mathrm{~h}$. Three measurements were made for each stone.

We completed our study of the pore system by calculating the degree of interconnection among pores $\left(A_{x}\right)$ and the saturation coefficient $(S) . A_{x}$ is the ratio between free and forced water absorption: high values indicate bad pore interconnection (Cultrone et al 2003). $S$ relates the saturation capacity of stones within $48 \mathrm{~h}$ of being immersed in distilled water. For this coefficient we followed the recommendations of RILEM (1980).

The mineralogy was determined on a fraction of less than $2 \mu \mathrm{m}$ of the insoluble waste obtained from each stone. For this purpose, we prepared approximately $100 \mathrm{~g}$ of sample, which was partially ground down and placed in a vessel with distilled water. The samples were then treated over several cycles (until no reaction process could be observed), with acetic acid $\left(\mathrm{CH}_{3} \mathrm{COOH}\right)$ to eliminate the carbonates with a concentration of equal to or less than $1 \mathrm{~N}$. Once this task had been completed, we added hydrogen peroxide $\left(\mathrm{H}_{2} \mathrm{O}_{2}\right)$ at $20 \%$ volume to eliminate any possible organic matter in the samples. Lastly after washing several times to eliminate the acid in the water, we added sodium hexametaphosphate to separate any aggregates that may have formed. After this procedure, the samples were concentrated by removing excess water and we obtained the fraction of less than $2 \mu \mathrm{m}$ using a Kubota KS-8000 centrifuge. Once we had obtained the clay fraction, we deposited it on a glass sample-holder using the oriented aggregate method (AO). We also prepared oriented aggregates in order to solvate them for $48 \mathrm{~h}$ at $60{ }^{\circ} \mathrm{C}$ with ethylene-glycol (AO-EG) (Bruton 1955), so as to evaluate the presence of swellable clays; with dimethyl-sulfoxide for $72 \mathrm{~h}$ to $80^{\circ} \mathrm{C}$ (AODMSO) (Gonzalez-Garcia and Sanchez-Camazano 1968) in order to identify the kaolinite and lastly, heat them at $550{ }^{\circ} \mathrm{C}$ for $90 \mathrm{~min}$ (AO-550) (Moore and Reynolds 1989) to check whether there is any chlorite. Each AO was analysed with $\mathrm{X}$ ray diffraction (XRD) using a Philips X'Pert PRO system. The following working conditions applied: radiation $\mathrm{Cu} K \alpha(\lambda=$ $1.5405 \AA$ ), voltage $45 \mathrm{kV}$, current $40 \mathrm{~mA}$, scanning angle $3-$ $30^{\circ} 2 \theta$ and a goniometer speed $0.12 \theta \mathrm{s}^{-1}$. We interpreted the results using the XPowder@ software (Martin 2004).

The compactness of the stones was appraised in dynamic and static modes. In the first case, the measurement was performed by ultrasounds under controlled thermohygrometric conditions $\left(\sim 20{ }^{\circ} \mathrm{C}\right.$ and relative humidity of $\sim 50 \%$ ) with a Panametrics HV Pulser/Receiver 5058PR coupled with a Tektronix TDS 3012B oscilloscope. The measurements were performed on 15 cube samples per stone type ( $5 \mathrm{~cm}$ edge) and in three orthogonal directions: direction 1 perpendicular to the surfaces of sedimentation and directions 2 and 3 parallel to these surfaces. The propagation velocity of compressional $\left(V_{P}\right)$ and shear $\left(V_{S}\right)$ pulses was measured in accordance with the ASTM D 2845-05 (2005) standard for dry test samples using polarized Panametrics transducers of $1 \mathrm{MHz}$ with a contact surface of $3 \mathrm{~cm}$ in diameter. A viscoelastic couplant was used to obtain a good coupling between the transducers and the stone surfaces. The transmission method 
was used and three measurements were taken for each orthogonal direction of the cube-shaped samples. Once we had established the wave velocities $\left(V_{P}\right.$ and $\left.V_{S}\right)$, we calculated the Poisson coefficient $(v)$ and the Young $(E)$, shear $(G)$ and bulk $(K)$ modules, which are useful when trying to predict the deformation behaviour of building materials (Gonzalez de Vallejo et al 2002) according to the following equations:

$$
\begin{aligned}
v & =\frac{\left(V_{P} / V_{S}\right)^{2}-2}{2\left[\left(V_{P} / V_{S}\right)^{2}-1\right]}, \\
E & =2 \rho_{b} V_{S}^{2}(1+v), \\
G & =\frac{E}{2(1-2 v)}, \\
K & =\frac{E}{3(1-2 v)},
\end{aligned}
$$

where $\rho_{\mathrm{b}}$ is the apparent density determined by MIP. Although these formulae are better suited to homogeneous and isotropic mediums, but the error in the measurement of our samples is the same for the six types of rock, and we can therefore make comparisons between them.

$V_{P}$ values were also useful for defining the total $(\Delta M)$ and relative $(\Delta m)$ anisotropies (Guydader and Denis 1986) as follows:

$$
\begin{aligned}
\Delta M & =\left(1-\frac{2 V_{P \text { min }}}{V_{P \text { max }}+V_{P \text { mean }}}\right) \times 100, \\
\Delta m & =\frac{2\left(V_{P \text { max }}-V_{P \text { mean }}\right)}{V_{P \text { max }}+V_{P \text { mean }}} \times 100,
\end{aligned}
$$

where $V_{P \max }$ is the mean maximum velocity, $V_{P_{\min }}$ is the mean minimum velocity and $V_{P \text { mean }}$ is the mean intermediate velocity in any one of the three orthogonal directions.

In the second case (static mode), we performed the uniaxial compression test in accordance with the UNE-EN 1926 (1999) standard. We used four cube-shaped samples (5 cm-edge) for each stone. The samples were positioned with their stratification planes or bands, when present, perpendicular to the direction of the load. The compressive strength $R_{c}$ (in MPa) was calculated according to the following formula:

$$
R_{c}=\frac{F}{A}
$$

where $F$ is the break load (in N) and $A$ is the area of the transversal section of the sample before testing (in $\mathrm{mm}^{2}$ ).

The durability of each stone was evaluated in the laboratory using the freeze-thaw and the salt crystallization accelerated aging tests. In the first case, frost damage was analysed according to the UNE-EN 12371 (2003) standard. Three samples per stone were used. The samples were cubic in shape with sides measuring $5 \mathrm{~cm}$. 25 cycles were performed. The salt crystallization test was performed according to the UNE-EN 12370 (2001) standard. Fifteen cycles were carried out on three samples per stone. Samples were the same shape and size as in the freeze-thaw test. The laboratory conditions were $20{ }^{\circ} \mathrm{C}$ and $30 \% \pm 5$ of relative humidity. The deterioration was monitored by controlling the weight change and the loss of fragments along the edges which had been painted prior to the experiment to facilitate observation of damage.
Both intact and altered samples after freeze-thaw and salt crystallization tests were evaluated using spectrophotometry to detect any possible chromatic change on their surfaces. When taking these measurements, the UNE-EN 15886 (2011) standard was followed and a Konica-Minolta CM-700d spectrophotometer was used. The CIELab system was chosen and $L^{*}$ (lightness, from 0 to 100 ), $\mathrm{a}^{*}$ and $\mathrm{b}^{*}$ (chromatism, from -60 to +60 ) parameters were calculated using reflectance values. The measurement conditions were as follows: a measurement area of $8 \mathrm{~mm}$, a D65 standard illuminant and observer $10^{\circ}$ with modes SCI/SCE and a wavelength range from 400 to $700 \mathrm{~nm}$ with a wavelength interval of $10 \mathrm{~nm}$. Ten measurements per stone were performed. Colour difference $\left(\Delta E_{94}{ }^{*}\right)$ was calculated with the following equation (UNE-EN 158862011 standard):

$$
\Delta E_{94}{ }^{*}=\left(\left(\frac{\Delta L^{*}}{k_{L} \cdot S_{L}}\right)^{2}+\left(\frac{\Delta C^{*}}{k_{C} \cdot S_{C}}\right)^{2}+\left(\frac{\Delta H^{*}}{k_{H} \cdot S_{H}}\right)^{2}\right)^{1 / 2} .
$$

The factors $\left(S_{L}, S_{C} y S_{H}\right)$ and the variables $\left(k_{L}, k_{C} y\right.$ $k_{H}$ ) in this equation weigh and correct the amplitude of the difference of colour perceived by modifying the lightness $\left(L^{*}\right)$, the chromatism $\left(C^{*}\right)$ and the tone $\left(H^{*}\right)$ of the chromatic space $L^{*} a^{*} b^{*}$.

Finally, in order to complete the information on the damage to the samples and to quantify the changes in the pore system produced by salt crystallization, we analysed a small fragment of each stone of about $1 \mathrm{~cm}^{3}$, using environmental scanning electron microscopy (ESEM). ESEM clearly showed the relationship between the growth of salt crystals in the pores and the cracks and the damage suffered by the stones. We used a Quanta 400 microscope coupled with energy dispersive $\mathrm{X}$-ray microanalysis (EDX). Using MIP we also compared the pore system of the altered samples, after freeze-thaw and salt crystallization tests, with that of intact ones.

\section{Results and discussion}

\subsection{Pore system of intact stones}

In table 1 we can see the pore size distribution in each rock within five size ranges $(<0.1,0.1-1,1-10,10-100$ and $>100 \mu \mathrm{m})$. These values were obtained using the porosimetric curves shown in figure 2 (curves I). For each range we can see the value of porosity $\left(P_{I}\right.$ in $\left.\%\right)$ with the relative porosity in square brackets, and the average pore entry radius for the mercury $(r)$. If we look at the results in table 1 and figure 2 we can see that SP has the highest percentage of porosity and a bimodal distribution with maximum values in the $0.1-1$ and $10-100 \mu \mathrm{m}$ ranges, which cover almost $65 \%$ of the porosity of this rock. This distribution into two main families in SP is due to the fact that the pores of less than $1 \mu \mathrm{m}$ belong to the intraparticular pores associated with the chambers of the skeletal remains (bryozoa and red algae), while the larger pores (over $1 \mu \mathrm{m}$ ) are found mainly in interparticle spaces and inside the skeletons of organisms (bryozoa and serpulidae). Most of the pores in the Fraga limestone (CF, 74.4\%) were in the range $0.1-1 \mu \mathrm{m}$ in a clearly unimodal distribution. This high percentage could be a problem for resistance to 
Table 1. The values for open porosity $(P$, in $\%)$ and their standard deviation for the three measurements are shown in brackets, bulk density $\left(\rho_{\mathrm{b}}\right.$, in $\left.\mathrm{kg} / \mathrm{m}^{3}\right)$, skeletal density $\left(\rho_{\mathrm{a}}\right.$, in $\left.\mathrm{kg} / \mathrm{m}^{3}\right)$, partial porosity $\left(P_{P}\right.$, in $\left.\%\right)$, the values in square brackets indicate the amount of relative porosity (in \%) and the mean pore size radius $(r$, in $\mu \mathrm{m})$ according to pore size ranges $(<0.1,0.1-1,1-10,10-100,>100 \mu \mathrm{m})$ of intact samples (I) and samples altered in the freeze-thaw (FT) and salt crystallization (Sa) tests, degree of pore interconnection $\left(A_{x}\right.$, in \%) and saturation coefficient $(S$, in \%). Legend: $\mathrm{SP}=$ Santa Pudia limestone, $\mathrm{TA}=$ Albox travertine, $\mathrm{DB}=\mathrm{Boñar}$ dolostone, $\mathrm{CF}=\mathrm{Fraga}$ limestone, $\mathrm{AU}=$ Uncastillo sandstone and $\mathrm{AV}=$ Villaviciosa sandstone.

\begin{tabular}{|c|c|c|c|c|c|c|c|c|c|c|c|c|c|c|c|c|}
\hline & & \multirow[b]{2}{*}{$P$} & \multirow[b]{2}{*}{$\rho_{\mathrm{b}}$} & \multirow[b]{2}{*}{$\rho_{\mathrm{a}}$} & \multicolumn{2}{|c|}{$<0.1$} & \multicolumn{2}{|l|}{$0.1-1$} & \multicolumn{2}{|c|}{$1-10$} & \multicolumn{2}{|c|}{$10-100$} & \multicolumn{2}{|c|}{$>100$} & \multirow[b]{2}{*}{$A_{x}$} & \multirow[b]{2}{*}{$S$} \\
\hline & & & & & $P_{P}$ & $r$ & $P_{P}$ & $r$ & $P_{P}$ & $r$ & $P_{P}$ & $r$ & $P_{P}$ & $r$ & & \\
\hline \multirow[t]{2}{*}{ SP } & I & $32.8(2.3)$ & 1725 & 2616 & $1.5(4.6)$ & 0.05 & $12.3(37.5)$ & 0.36 & 7.7 (23.4) & 4.38 & $9.6(29.4)$ & 39.86 & $1.7(5.0)$ & 138.49 & \multirow[t]{2}{*}{20.1} & \multirow[t]{2}{*}{71.3} \\
\hline & $\mathrm{Sa}$ & $34.1(0.2)$ & 1744 & 2649 & $0.3(1.0)$ & 0.06 & $9.6(28.2)$ & 0.58 & $7.6(22.2)$ & 3.62 & $40.0(13.6)$ & 21.70 & $3.0(8.7)$ & 191.93 & & \\
\hline \multirow[t]{3}{*}{ TA } & I & $7.6(1.2)$ & 2416 & 2624 & $3.5(45.5)$ & 0.03 & $1.9(25.4)$ & 0.30 & $0.7(9.7)$ & 0.92 & $1.2(15.4)$ & 44.54 & $0.3(4.0)$ & 140.61 & \multirow[t]{3}{*}{58.1} & \multirow[t]{3}{*}{37.3} \\
\hline & FT & $4.9(1.1)$ & 2544 & 2675 & $2.0(34.0)$ & 0.03 & $0.69(11.9)$ & 0.52 & $0.7(12.1)$ & 5.26 & $1.75(30.2)$ & 42.57 & $0.7(11.8)$ & 194.80 & & \\
\hline & $\mathrm{Sa}$ & $5.8(1.4)$ & 2568 & 2726 & $1.7(29.9)$ & 0.02 & $0.2(3.0)$ & 0.38 & $1.9(33.0)$ & 1.21 & $1.4(24.7)$ & 49.32 & $0.5(9.4)$ & 190.94 & & \\
\hline \multirow[t]{3}{*}{$\overline{\mathrm{DB}}$} & I & $10.1(2.5)$ & 2394 & 2721 & $3.9(38.1)$ & 0.04 & $5.6(55.5)$ & 0.36 & $0.3(3.0)$ & 3.24 & $0.3(2.6)$ & 41.71 & $0.1(0.8)$ & 144.38 & \multirow[t]{3}{*}{11.1} & \multirow[t]{3}{*}{79.2} \\
\hline & FT & $10.7(2.1)$ & 2541 & 2844 & $0.9(8.4)$ & 0.06 & $9.2(85.6)$ & 0.48 & $0.4(3.6)$ & 1.97 & $0.2(1.6)$ & 42.05 & $0.1(0.8)$ & 204.18 & & \\
\hline & $\mathrm{Sa}$ & $14.4(2.8)$ & 2392 & 2794 & $1.1(7.8)$ & 0.06 & $5.4(37.6)$ & 0.50 & $7.4(51.1)$ & 2.50 & $0.4(2.7)$ & 31.40 & $0.1(0.8)$ & 219.54 & & \\
\hline \multirow[t]{3}{*}{ CF } & I & $28.9(0.2)$ & 1875 & 2627 & $3.1(10.8)$ & 0.05 & $21.5(74.4)$ & 0.31 & $3.5(12.2)$ & 1.93 & $0.6(2.1)$ & 36.93 & $0.2(0.5)$ & 142.81 & \multirow[t]{3}{*}{4.0} & \multirow[t]{3}{*}{88.6} \\
\hline & FT & $24.2(0.9)$ & 1970 & 2663 & $0.7(2.8)$ & 0.07 & $16.2(67.1)$ & 0.44 & $6.0(24.8)$ & 2.31 & $1.0(4.3)$ & 33.23 & $0.2(1.0)$ & 192.23 & & \\
\hline & $\mathrm{Sa}$ & $26.5(0.4)$ & 1961 & 2668 & $0.7(2.5)$ & 0.09 & $18.8(71.0)$ & 0.44 & $5.2(19.5)$ & 2.68 & $1.5(5.6)$ & 38.85 & $0.3(1.1)$ & 202.92 & & \\
\hline \multirow[t]{3}{*}{$\mathrm{AU}$} & I & $17.8(1.2)$ & 2136 & 2616 & $1.7(9.5)$ & 0.04 & $2.2(12.6)$ & 0.45 & $8.6(48.2)$ & 5.78 & $5.0(28.1)$ & 19.33 & $0.3(1.6)$ & 143.49 & \multirow[t]{3}{*}{25.1} & \multirow[t]{3}{*}{68.1} \\
\hline & FT & $21.0(1.4)$ & 2114 & 2678 & $0.7(3.2)$ & 0.05 & $2.6(12.2)$ & 0.50 & $2.9(13.9)$ & 4.25 & $14.2(67.6)$ & 29.74 & $0.6(3.0)$ & 191.86 & & \\
\hline & $\mathrm{Sa}$ & $16.1(2.1)$ & 2162 & 2577 & $0.7(4.1)$ & 0.05 & $1.6(9.7)$ & 0.41 & $4.3(26.6)$ & 5.82 & $9.2(57.2)$ & 21.34 & $0.4(2.4)$ & 226.90 & & \\
\hline \multirow{2}{*}{$\mathrm{AV}$} & FT & $16.5(0.9)$ & 2185 & 2618 & $0.4(2.4)$ & 0.05 & $1.2(7.1)$ & 0.35 & $6.4(39.0)$ & 6.33 & $7.8(47.3)$ & 25.43 & $0.7(4.3)$ & 193.98 & \multirow{2}{*}{41.5} & \multirow{2}{*}{46.1} \\
\hline & $\mathrm{Sa}$ & $17.4(0.2)$ & 2179 & 2637 & $0.3(1.8)$ & 0.06 & $1.2(7.0)$ & 0.48 & 6.7 (38.6) & 6.85 & $8.5(49.1)$ & 25.46 & $0.6(3.6)$ & 193.83 & & \\
\hline
\end{tabular}

ice and above all to salt crystallization, since rocks with a high percentage of small pores are more susceptible to alteration (Rodriguez Navarro and Doehne 1999). AU and AV sandstones had very similar porosity values, and a similar unimodal pore size distribution. The only difference is that $\mathrm{AV}$ had a higher percentage of pores of more than $10 \mu \mathrm{m}$ compared to AU. Finally, TA and DB samples had the lowest porosity in comparison with the other four stones, they had a high concentration of small pores, above all of less than $0.5 \mu \mathrm{m}$ and the porosimetric curves were irregularly distributed and not as well defined as in the other rocks.

As regards density values $\left(\rho_{\mathrm{b}}\right.$ and $\rho_{\mathrm{s}}$, table 1$)$, the SP and CF samples show the highest differences between the $\rho_{\mathrm{b}}$ and $\rho_{\mathrm{s}}$ values due to their high porosity level. By contrast, the differences between the two densities are much smaller in TA and DB. The highest skeletal density belongs to DB as it is made up above all of dolomite, whereas the lowest value is for $\mathrm{AV}$, due to the fact that its grains are mainly composed of quartz plus small amounts of feldspar.

TA shows the highest $A_{x}$ value (table 1), which means that its pores are the least interconnected. This explains why the travertine has the lowest saturation coefficient $(S$, table 1$)$. Considering also that it has low open porosity, this could be an advantage. $\mathrm{CF}$, on the contrary, has the lowest $A_{x}$ value (table 1), which means that most of the pores are well connected, allowing the stone to saturate almost completely in just $48 \mathrm{~h}(88.6 \%$, table 1$)$. In the case of $\mathrm{DB}$, although it has a low porosity (approximately 10\%), its porous system is wellconnected and it has a high level of saturation (79.2\%, table 1). Rocks SP and AU had similar values for $A_{x}$ and for $S$, in spite of the difference in porosity between the two rocks. Lastly, AV obtained similar $A_{x}$ and $S$ values to TA, which indicates that although it has a porosity of almost $20 \%$, its porous system is poorly connected, which means that it is difficult for the empty spaces to fill with water.

\subsection{Mineralogical characterization of the insoluble residue}

Table 2 shows the percentage of the carbonated fraction in each sample (CB), the insoluble residue greater than $2 \mu \mathrm{m}$ (IR $>2 \mu \mathrm{m}$ ) and less than $2 \mu \mathrm{m}$ (IR $<2 \mu \mathrm{m})$. As regards these percentages, as one might expect SP, TA and CF to have the largest carbonated fraction. In DB, the value obtained covers both the proportion of dolomite and that of calcite. As commented previously in the description of the materials, AU has approximately similar proportions of carbonated and siliceous material. AV is notable for its total lack of carbonates, and this is why it has the highest IR value.

As regards the fraction of less than $2 \mu \mathrm{m}$, in general, the most abundant mineral is illite. Kaolinite was also detected in almost all the samples. Chlorite however only appeared in SP, CF and AU and paragonite only in TA. Lastly, smectites were detected in SP and AU, due to the increase in the reticular spacing caused by solvatation with ethylene-glycol. The swelling caused by the presence of smectites may produce additional stress in the samples, leading to a degradation of the mechanical properties of the material over time. However, given that two natural stones are never identical, we know that the presence of smectites can cause variations in the intrinsic properties of the stones. In fact, in Vazquez et al (2013) the percentage of clay fraction was higher than in our case. Thus, although our selection was representative, there may be significant variations between samples, depending on the material selected at the quarry face.

The addition of hydrogen peroxide revealed that there was organic matter (OM, table 2) in the SP, CF and AU samples. In $\mathrm{SP}$ and $\mathrm{AU}$, the reaction was weak due to the low concentration of organic matter. In CF however the reaction lasted for various cycles and was more intense than in the other two cases. 

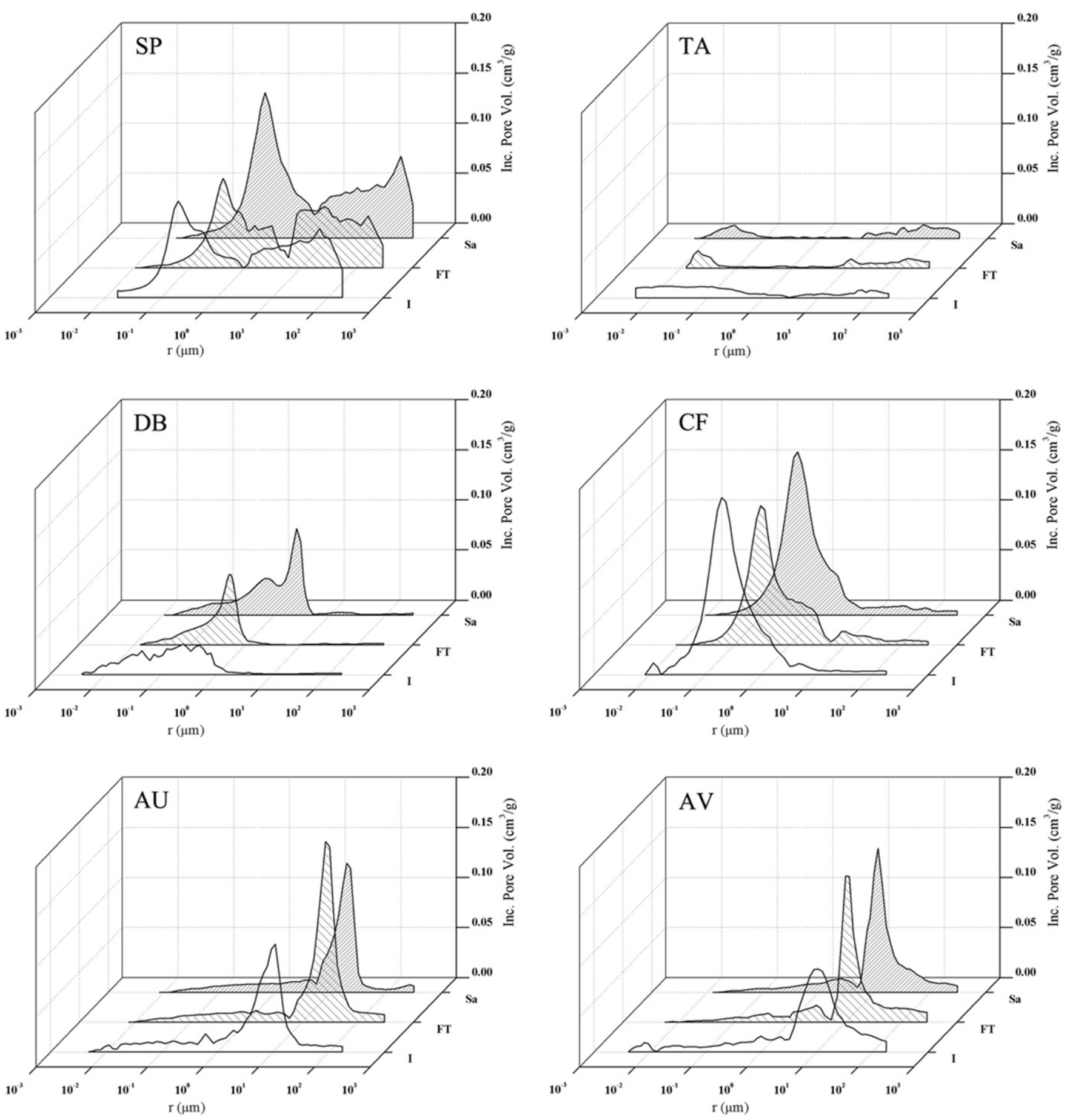

Figure 2. Pore size distribution curves for intact (I) and altered specimens after freeze-thaw (FT) and salt crystallization (Sa) tests on Santa Pudia limestone (SP), Albox travertine (TA), Boñar dolostone (DB), Fraga limestone (CF), Uncastillo sandstone (AU) and Villaviciosa sandstone $(\mathrm{AV})$. Pore entry radius (in $\mu \mathrm{m}$ ) versus incremental pore volume (in $\mathrm{cm}^{3} / \mathrm{g}$ ). Each curve is a mean of the three measurements made per stone.

\subsection{Compactness}

The six types of rock have different elastic behaviour, as might be expected given that this parameter is influenced by the mineralogical composition, the porosity and the rock fabric of the materials. TA shows the highest $V_{P}$ and $V_{S}$ values (table 3 and figure 3, columns I). This is mainly due to the low porosity and high compactness of the rock, which facilitates the propagation of the ultrasonic waves. However, this type of rock is also characterized by some large empty spaces known as 'vuggy porosity' (Benavente 2011), which do not interfere with the waves because these always travel along the fastest path, i.e. through solid material (MartinezMartinez 2008). The velocity for DB is lower than that obtained in the TA samples, although it is the second highest of the six stones and has a very low deviation, which indicates a high degree of homogeneity between the samples. The SP 
Table 2. Percentage of the principal compounds and the mineral composition of the clay fraction $(<2 \mu \mathrm{m})$ of each stone. Legend: carbonates (in \%), insoluble fraction greater than $2 \mu \mathrm{m}$ (IR $>2 \mu \mathrm{m}$, in \%), insoluble fraction below $2 \mu \mathrm{m}$ (IR $<2 \mu \mathrm{m}$, in $\%$ ), organic matter $(\mathrm{OM})$, illite (Il), smectite $(\mathrm{Sm})$, chlorite $(\mathrm{Chl})$, kaolinite $(\mathrm{K})$, paragonite $(\mathrm{Pa})$. The amount of each material has been expressed as follows: none $(-)$, traces $(\operatorname{tr})$, small quantities $(x)$, large quantities $(x x)$ and very large quantities $(x x x)$. For stone acronyms see table 1.

\begin{tabular}{|c|c|c|c|c|c|c|c|c|c|}
\hline & \multirow[b]{2}{*}{ Carbonates } & \multirow[b]{2}{*}{$\mathrm{IR}>2 \mu \mathrm{m}$} & \multirow[b]{2}{*}{$\mathrm{IR}<2 \mu \mathrm{m}$} & \multirow[b]{2}{*}{$\mathrm{OM}$} & \multicolumn{5}{|c|}{ IR $<2 \mu \mathrm{m}$ (clay minerals) } \\
\hline & & & & & Il & $\mathrm{Sm}$ & Chl & K & $\mathrm{Pa}$ \\
\hline SP & 97 & 0.7 & 1.5 & $\mathrm{Tr}$ & $x / x x$ & $x x x$ & $\operatorname{tr}$ & $x / x x$ & - \\
\hline TA & 98 & 0.7 & 0.5 & - & $x x x$ & - & $\operatorname{tr}$ & $\operatorname{tr}$ & $x / x x$ \\
\hline DB & 80 & 18.5 & 0.8 & - & $x x$ & - & - & $x x / x x x$ & - \\
\hline $\mathrm{CF}$ & 94 & 4.8 & 0.2 & $x x x$ & $x x$ & - & $x x$ & $x$ & - \\
\hline $\mathrm{AU}$ & 44 & 54.1 & 1.3 & $x$ & $x x x$ & $x x$ & $x$ & $x x x$ & - \\
\hline $\mathrm{AV}$ & 0 & 98.9 & 0.6 & - & $x x$ & - & $\operatorname{tr}$ & $x$ & - \\
\hline
\end{tabular}

Table 3. $P$ - and $S$-wave velocity values $\left(V_{P}\right.$ and $V_{S}$, in $\left.\mathrm{m} / \mathrm{s}\right)$, Poisson coefficient $(v)$, shear module $(G$, in GPa), Young module $(E$, in GPa), volume module $(K$, in $\mathrm{GPa})$, relative $(\Delta m)$ and total $(\Delta M)$ anisotropy coefficients and compressive strength $\left(R_{c}\right.$, in MPa). The standard deviation of three measurements is shown in brackets. For stone acronyms see table 1 .

\begin{tabular}{llllllllllll}
\hline & $V_{P}$ & $V_{S}$ & $v$ & $G$ & $E$ & $K$ & $\Delta m_{P}$ & $\Delta M_{P}$ & $\Delta m_{S}$ & $\Delta M_{S}$ & $R_{C}$ \\
\hline SP & 3593 & 1730 & 0.35 & 5.2 & 14.1 & 23.6 & 3.0 & 9.5 & 3.1 & 3.9 & 11 \\
& $(313)$ & $(72)$ & $(0.02)$ & $(0.4)$ & $(1.3)$ & $(5.3)$ & $(2.3)$ & $(5.0)$ & $(2.6)$ & $(1.8)$ & $(2)$ \\
\hline TA & 5553 & 2729 & 0.34 & 17.6 & 47.2 & 74.2 & 3.6 & 5.1 & 2.7 & 3.8 & 69 \\
& $(194)$ & $(98)$ & $(0.02)$ & $(1.3)$ & $(3.1)$ & $(7.2)$ & $(1.9)$ & $(3.2)$ & $(1.4)$ & $(1.6)$ & $(9)$ \\
\hline DB & 4425 & 2572 & 0.24 & 16.5 & 40.9 & 40.1 & 1.3 & 1.8 & 0.6 & 2.6 & 140 \\
& $(79)$ & $(49)$ & $(0.01)$ & $(0.7)$ & $(1.5)$ & $(2.3)$ & $(1.1)$ & $(1.4)$ & $(0.4)$ & $(0.8)$ & $(21)$ \\
\hline CF & 3186 & 1780 & 0.27 & 5.9 & 15.0 & 16.7 & 4.8 & 7.8 & 2.6 & 2.8 & 22 \\
& $(204)$ & $(43)$ & $(0.04)$ & $(0.3)$ & $(0.9)$ & $(3.4)$ & $(2.3)$ & $(3.5)$ & $(3.0)$ & $(1.8)$ & $(3)$ \\
\hline AU & 2549 & 1588 & 0.17 & 5.6 & 13.0 & 10.4 & 4.0 & 11.6 & 5.5 & 5.2 & 20 \\
& $(199)$ & $(99)$ & $(0.06)$ & $(1.0)$ & $(2.4)$ & $(2.7)$ & $(2.9)$ & $(5.0)$ & $(1.5)$ & $(2.7)$ & $(4)$ \\
\hline AV & 2593 & 1695 & 0.12 & 6.1 & 13.7 & 9.3 & 6.3 & 5.1 & 1.2 & 1.5 & 71 \\
& $(101)$ & $(28)$ & $(0.05)$ & $(0.2)$ & $(0.6)$ & $(1.7)$ & $(1.3)$ & $(1.8)$ & $(0.9)$ & $(1.7)$ & $(7)$ \\
\hline
\end{tabular}

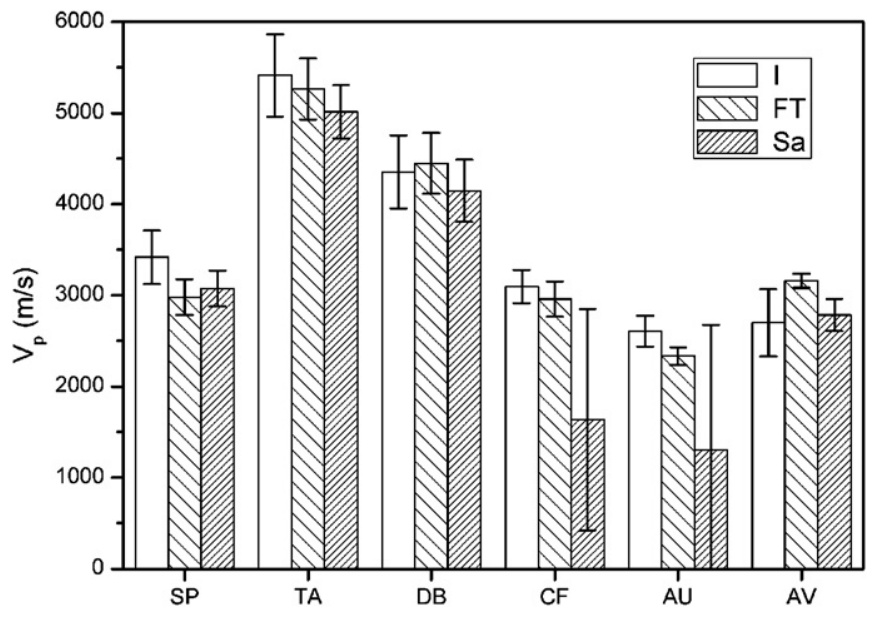

Figure 3. Histogram showing the mean $V_{P}$ (in $\mathrm{m} / \mathrm{s}$ ) values for intact samples (I) and after finishing the freeze-thaw (FT) and the salt crystallization (Sa) tests for each rock (except for SP and CF in the freeze-thaw test, see text). The vertical bar in each column shows the standard deviation value. For stone acronyms see figure 1 .

and CF samples have quite similar $V_{p}$ values because they have a similar composition and porosity. The fact that the values are slightly lower in CF may be due to the presence of organic matter in this rock. The lowest velocity values were found in the two sandstones, $\mathrm{AU}$ and $\mathrm{AV}$ (table 3), due to the fact that their mineralogical composition is predominantly silicate-based and to a lesser extent to the porosity level and the type of rock fabric.

As regards total anisotropy ( $\Delta M$, table 3 ), AU showed the highest value which indicates that in larger blocks of rock a preferential orientation of the sedimentation planes would be appreciable, even though in our samples this was not visible at a macroscopic level. It is important to bear in mind that a high $\Delta M$ value indicates that at least one of the three directions of the sample has a lower ultrasound propagation speed. This could indicate a direction that is more prone to alteration processes, due to the presence of discontinuities (Fort et al 2011). SP had a high $\Delta M$ value which suggests that in this case too the rock fabric has a certain degree of orientation, something which cannot be seen with the naked eye. $\mathrm{CF}$ also had a medium-high $\Delta M$ value (7.8, table 1$)$. DB however showed lower values due to its low open porosity $\left(P_{I}\right.$, table 1$)$ and to the fact that it underwent a process of dolomitization, which could reduce or in this case delete its original orientations and anisotropies. According to GomezFernandez et al (2003), the strata of the dolostone (DB) are homogeneous and the only discontinuities are the planes that limit or cut these strata.

The mineralogy of the rocks influences the Poisson coefficient ( $v$, table 3) (Christensen 1996, Brocher 2005). In fact, previous research has shown that rocks composed of calcite show higher $v$ values than rocks rich in quartz (Ji et al 2009). This appears to be the case, as AV which is composed mainly of quartz and feldspars has the lowest $v$ value $(0.12$, 
Table 4. Average values for variation in weight $(\triangle W$, in $\%)$ and $P$-wave velocity $\left(V_{P}\right.$, in $\left.\mathrm{m} / \mathrm{s}\right)$ for the freeze-thaw test. The standard deviation $(\sigma)$ and the variation in $P$-wave velocity $\left(\triangle V_{p}\right.$, in \%) compared to the first measurement are indicated. The table shows the variation in weight every five cycles with the corresponding wave velocity measurement. For stone acronyms see table 1.

\begin{tabular}{|c|c|c|c|c|c|c|c|c|c|c|c|c|c|c|c|}
\hline CYCLE & & SP & $\mathrm{TA}$ & DB & $\mathrm{CF}$ & $\mathrm{AU}$ & AV & CYCLE & & SP & TA & DB & $\mathrm{CF}$ & $\mathrm{AU}$ & AV \\
\hline 5 & $\begin{array}{l}\triangle W \\
\sigma \\
\end{array}$ & $\begin{array}{l}16.04 \\
(0.58) \\
\end{array}$ & $\begin{array}{l}2.03 \\
(0.16) \\
\end{array}$ & $\begin{array}{l}3.90 \\
(0.96) \\
\end{array}$ & $\begin{array}{l}14.84 \\
(0.97) \\
\end{array}$ & $\begin{array}{l}7.76 \\
(0.11) \\
\end{array}$ & $\begin{array}{l}3.96 \\
(0.09) \\
\end{array}$ & 5 & $\Delta V_{p}$ & -10.7 & -8.1 & -4.5 & 0.2 & -6.3 & -2.1 \\
\hline 10 & $\begin{array}{l}\triangle W \\
\sigma\end{array}$ & $\begin{array}{l}16.88 \\
(0.51) \\
\end{array}$ & $\begin{array}{l}2.28 \\
(0.15) \\
\end{array}$ & $\begin{array}{l}4.20 \\
(1.00)\end{array}$ & $\begin{array}{l}15.16 \\
(1.39) \\
\end{array}$ & $\begin{array}{l}8.47 \\
(0.42) \\
\end{array}$ & $\begin{array}{l}4.77 \\
(0.04)\end{array}$ & 10 & $\Delta V_{p}$ & -12.2 & -5.1 & -6.1 & -1.7 & -8.7 & -2.5 \\
\hline 15 & $\begin{array}{l}\triangle W \\
\sigma\end{array}$ & $\begin{array}{l}16.72 \\
(0.84) \\
\end{array}$ & $\begin{array}{l}2.29 \\
(0.15) \\
\end{array}$ & $\begin{array}{l}4.22 \\
(1.04) \\
\end{array}$ & $\begin{array}{l}14.67 \\
(2.45) \\
\end{array}$ & $\begin{array}{l}8.67 \\
(0.50) \\
\end{array}$ & $\begin{array}{l}5.05 \\
(0.05) \\
\end{array}$ & 15 & $\Delta V_{p}$ & - & -1.3 & -0.3 & 1.6 & -8.5 & 3.4 \\
\hline 20 & $\begin{array}{l}\Delta W \\
\sigma \\
\end{array}$ & $\begin{array}{l}13.86 \\
(6.30) \\
\end{array}$ & $\begin{array}{l}2.41 \\
(0.12) \\
\end{array}$ & $\begin{array}{l}4.41 \\
(1.08) \\
\end{array}$ & $\begin{array}{l}11.60 \\
(9.02) \\
\end{array}$ & $\begin{array}{l}9.10 \\
(0.49) \\
\end{array}$ & $\begin{array}{l}5.29 \\
(0.06) \\
\end{array}$ & 20 & $\Delta V_{p}$ & - & -0.2 & -0.6 & - & -2.3 & 5.6 \\
\hline 25 & $\begin{array}{l}\triangle W W \\
\sigma\end{array}$ & $\begin{array}{r}-25.17 \\
(7.29)\end{array}$ & $\begin{array}{l}2.46 \\
(0.10)\end{array}$ & $\begin{array}{l}4.48 \\
(1.11)\end{array}$ & $\begin{array}{c}-14.42 \\
(12.88)\end{array}$ & $\begin{array}{l}9.26 \\
(0.61)\end{array}$ & $\begin{array}{l}5.33 \\
(0.07)\end{array}$ & 25 & $\Delta V_{\mathrm{p}}$ & - & -5.6 & -6.7 & - & -24.3 & -3.1 \\
\hline
\end{tabular}

table 3), followed by AU, which contains quartz and calcite in similar concentrations. The other four stones are composed of carbonates and $v$ is considerably higher, especially in SP and TA (table 3). Although CF is also a carbonated rock, the fact that it has a low $v$ value is probably due to the presence of minerals such as clay, which tend to reduce this coefficient (Benavente 2002).

There were similar results for the shear $(G)$ and the Young (E) modules, with the TA and DB (rocks with a crystalline rock fabric) samples showing highest resistance. The other four stones have very similar values. As regards the volume module $(K)$, the greatest compressive strength was obtained in TA, followed some way behind by DB, while the weakest rocks were the two sandstones (AV and AU) (table 3 ).

If we compare the results set out in table 3 , the most compact, most homogeneous rock was DB. At the other extreme, the AU and AV rocks had the lowest ultrasound velocity values, and SP and AU had the highest presence of discontinuities that produce a high anisotropy coefficient compared to the other stones.

\subsection{Compressive strength}

The greatest compressive strength $\left(R_{c}\right.$, table 3$)$ was found in DB (140 MPa), while the lowest was in SP (11 MPa) due to its high porosity and the fact that there is little cement between the clasts (Luque et al 2008). In the case of DB, it seems that dolomitic rocks with low porosity have a higher compressive strength than those composed of calcite (Carmichel 1989, Gonzalez de Vallejo et al 2002, Martinez-Martinez 2008). TA (69 MPa) and AV (71 MPa) scored medium values between the two extremes, while AU and CF were at the bottom of the ranking and obtained similar, low values for compressive strength of 20 and $22 \mathrm{MPa}$, respectively.

Figure 4 compares the porosity of each rock against its compressive strength. The standard deviation of the porosity $(\sigma$, table 1$)$ and the compressive strength $(\sigma$, table 3 ) have also been added. As we can see, the SP, CF and AU stones have the lowest compressive strength values. In SP and CF this is due to their high porosity level, which directly limits their capacity to resist compression, and this is why both have a low dispersion of $R_{c}$ values. It is interesting to note that although TA and DB have similar porosity levels, they have quite different results

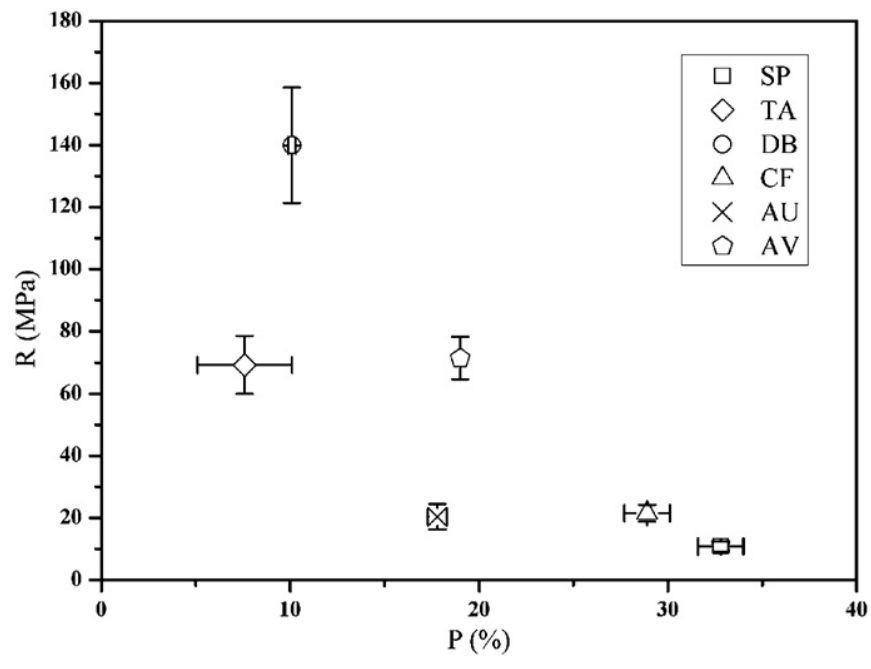

Figure 4. Representation of the average porosity values (in \%) for each stone compared to its average compressive strength (in MPa). The vertical and horizontal bars are the standard deviation for porosity and compressive strength values, respectively. For stone acronyms see figure 1 .

for compressive strength, with TA scoring only half that of DB. This is due to the 'vuggy pores' in TA mentioned earlier, which reduce compressive strength considerably, leading to a substantial dispersion of the $R_{c}$ values; in the case of $\mathrm{DB}$, this greater dispersion is due to the fact that this rock may have stylolites and small discontinuous veins (Vazquez et al 2013), which, according to their abundance, lead to a reduction in the resistance of the rock under load. In a similar way, the two sandstones (AU and AV) have quite similar porosity values (table 1), but AU has a lower compressive strength because of its marked anisotropy ( $\Delta M$, table 3$)$ and because the grains are well-cemented in AV. AU obtained the least dispersed $R_{c}$ and $P$ values. AV however showed greater dispersion of the $R_{c}$ coefficient due to the degree of cementation of the rock and the degree of alteration shown by the feldspars.

\subsection{Durability to freeze-thaw}

The samples behaved in two different ways in this test (table 4 and figure 5): one group made up of the TA, DB, AU and $\mathrm{AV}$ stones suffered no damage, whereas the other two stones, 


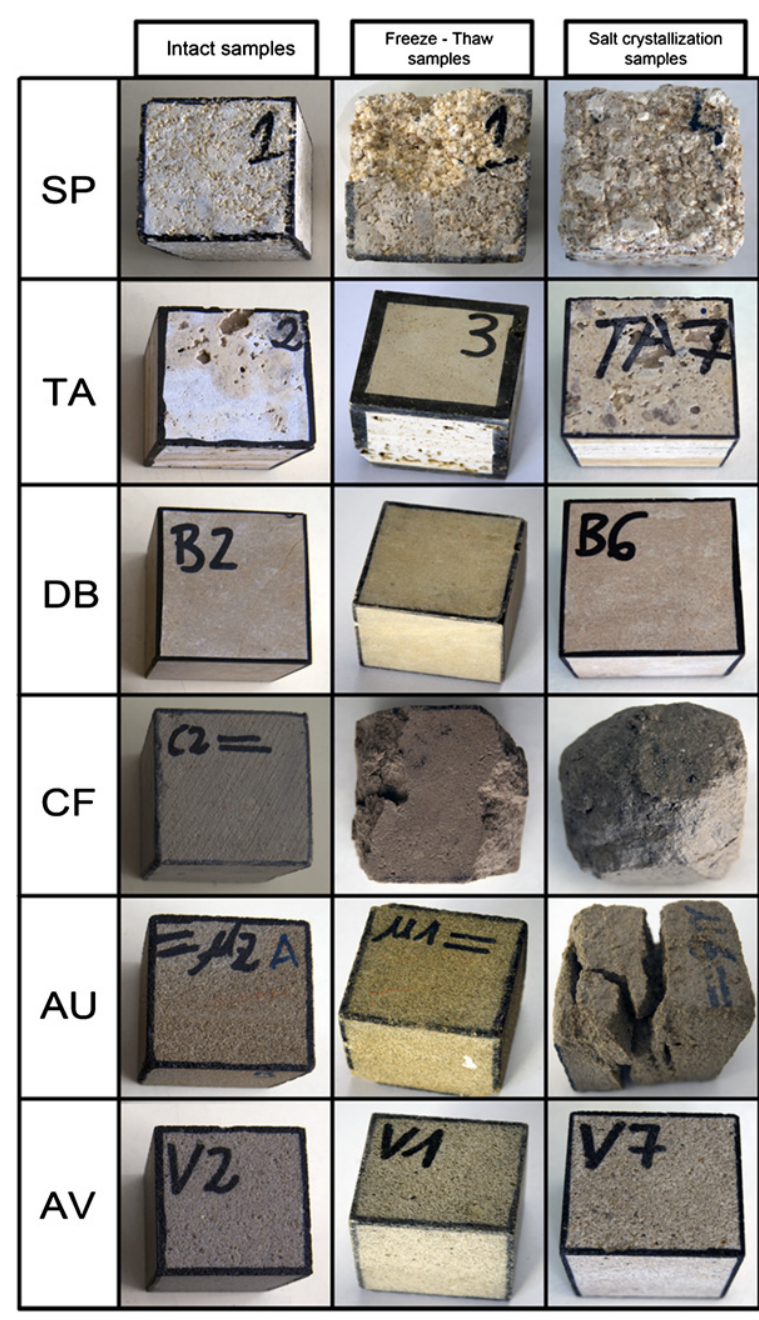

Figure 5. Photographs of the six stone types before and after freeze-thaw and salt crystallization cycles. The samples are cubes with sides measuring $5 \mathrm{~cm}$. Stone abbreviations are indicated in figure 1 .

SP and CF, lost a considerable amount of material. At the beginning of the test (over the first five cycles) water absorption in the stones that were not damaged varied according to their porosity. This was followed by a slow saturation of the test samples without them undergoing any important changes. SP and CF behaved in the same way as the other stones at first, but in SP, fragments broke off gradually between cycles 15 and 20 (figure 5). Given that the interclastic cement is very low in this stone, the ice easily causes superficial clasts to break off and gradually gets deeper into the stone. After cycle 20 , the loss of material was increasingly severe and by the end of the test it had lost almost a quarter of its initial mass. The decay suffered by this rock during the first cycles could be classified as sanding, while later on it was more intense and the rock started splintering (ICOMOS 2008). CF was less affected than SP (figure 5). During the initial cycles, decay occurred at specific points and could be described as bursting (ICOMOS 2008). Between cycles 15 and 20, there was a more obvious loss of material. With the naked eye we could see small fragments breaking off and cracks beginning to appear. The most important decay process during these cycles could be defined as chipping (ICOMOS 2008). These cracks caused a slight weight increase in the samples at around cycle 20 due to the fact that more water could get inside. This was followed later by a substantial loss of mass as large fragments began to break off as a result of the cracking.

There is a clear relation between the alteration produced by the effects of the ice inside the samples and the $A_{x}$ and $S$ coefficients from table 1 . The high $S$ value in SP for example indicates that most of its pore system is full of water and that it fills up quickly (high degree of interconnection between the pores, $A_{x}$ ), which together with its lack of interclastic cement makes it more susceptible to damage by freeze-thaw. According to the capillary pressure model described by Everett (1961) ice crystallization begins in the largest pores. In our case, SP has a lot of large pores, which would explain its poor behaviour when exposed to ice. The samples are saturated in water and as a result the pressure exercised by the water when it crystallizes is approximately the same throughout the sample, which in SP led to large fragments breaking off. The fact that the damage takes place in a large part of the volume of the sample and not at one specific point, is a characteristic finding in this kind of test (Scherer 1999). In addition and as was seen by XRD, this rock had a substantial amount of smectites, which can produce additional stress. CF suffers a similar decay process as SP because of its porous system, but it has a higher $S$ coefficient and a lower $A_{x}$ value, which means that more water can get inside it more easily but with smaller pore size. The most serious damage during the freeze-thaw test normally occurs in the rocks with a high saturation coefficient. This phenomenon was observed by various previous authors in studies on different kinds of rocks (Chen et al 2004, Ruedrich and Siegesmund 2007) and occurred in a similar way to our case. The exception in our study is DB. Although it has a good $A_{x}$ coefficient and a high $S$ coefficient, the porosity is low and its compactness is very high which makes it highly resistant to damage by ice. By contrast, in TA the combination of low open porosity with a very high $A_{x}$ value (low interconnection between the pores) may explain its good performance when exposed to ice crystallization inside the pores. Finally, both sandstones have similar porosity but different $A_{x}$ and $S$ coefficients. Their resistance to ice crystallization is due to extensive cementation between the grains in AU and to the fact that the pore system in $\mathrm{AV}$ is poorly connected.

Using ultrasounds, we were able to monitor periodically (every five cycles) the damage suffered by the samples $\left(V_{P}\right.$, table 4). The TA, DB and AV samples only suffered a slight fall in $V_{P}$. However in all the stones except $\mathrm{CF}$, the velocity was lower at the first measurement point (cycle 5), something which occurred most clearly in TA. Velocity increased again however at the second reading (cycle 10) only to fall back again at the fifth measurement point (cycle 25). These variations are due to the opening of pores and/or fissures that are not visible to the naked eye (cycle 5), to the crystallization of ice inside the samples (cycle 10) and to the opening of new fissures (cycle 25). In the case of AU, there was a fall of almost $25 \%$ in the velocity of propagation over the last cycles of the test. This would suggest that new cracks had developed 
Table 5. Variations in weight $(\Delta W$ in $\%)$ and in $P$-wave velocity $\left(\Delta V_{P}\right.$, in $\left.\%\right)$ during the salt crystallization test. The standard deviation $(\sigma)$ is shown. The table shows the values for variation in weight every five cycles with their corresponding ultrasound velocity measurement. For stone acronyms see table 1 .

\begin{tabular}{|c|c|c|c|c|c|c|c|c|c|c|c|c|c|c|c|}
\hline CYCLE & & SP & TA & DB & $\mathrm{CF}$ & $\mathrm{AU}$ & $\mathrm{AV}$ & CYCLE & & SP & TA & DB & $\mathrm{CF}$ & $\mathrm{AU}$ & AV \\
\hline 5 & $\begin{array}{l}\triangle W \\
\sigma \\
\end{array}$ & $\begin{array}{c}-4.29 \\
(0.72) \\
\end{array}$ & $\begin{array}{l}0.17 \\
(0.06) \\
\end{array}$ & $\begin{array}{l}0.17 \\
(0.11) \\
\end{array}$ & $\begin{array}{r}-10.33 \\
(5.63) \\
\end{array}$ & $\begin{array}{r}-1.87 \\
(0.82) \\
\end{array}$ & $\begin{array}{l}0.38 \\
(0.02) \\
\end{array}$ & 5 & $\triangle V_{p}$ & 1.1 & 8.4 & 4.3 & -10.0 & 3.4 & 16.7 \\
\hline 10 & $\begin{array}{l}\triangle W \\
\sigma \\
\end{array}$ & $\begin{array}{r}-4.71 \\
(0.66) \\
\end{array}$ & $\begin{array}{l}0.35 \\
(0.14) \\
\end{array}$ & $\begin{array}{l}0.46 \\
(0.04) \\
\end{array}$ & $\begin{array}{r}-6.49 \\
(6.76) \\
\end{array}$ & $\begin{array}{c}-1.65 \\
(1.05) \\
\end{array}$ & $\begin{array}{l}0.71 \\
(0.04) \\
\end{array}$ & 10 & $\triangle V_{p}$ & 0.1 & -0.8 & 2.2 & -13.3 & 1.8 & 17.7 \\
\hline 15 & $\begin{array}{l}\Delta W \\
\sigma \\
\end{array}$ & $\begin{array}{r}-4.60 \\
(0.65) \\
\end{array}$ & $\begin{array}{l}0.41 \\
(0.11) \\
\end{array}$ & $\begin{array}{l}0.69 \\
(0.15) \\
\end{array}$ & $\begin{array}{r}-6.12 \\
(6.88) \\
\end{array}$ & $\begin{array}{r}-1.40 \\
(1.22) \\
\end{array}$ & $\begin{array}{l}1.05 \\
(0.09) \\
\end{array}$ & 15 & $\Delta V_{p}$ & -0.6 & 2.5 & 2.6 & -12.3 & 5.8 & 19.4 \\
\hline $\begin{array}{l}\text { Washing of } \\
\text { samples }\end{array}$ & $\begin{array}{l}\triangle W \\
\sigma\end{array}$ & $\begin{array}{r}-6.44 \\
(0.71)\end{array}$ & $\begin{array}{l}0.02 \\
(0.02)\end{array}$ & $\begin{array}{l}0.04 \\
(0.06)\end{array}$ & $\begin{array}{r}-16.63 \\
(8.02)\end{array}$ & $\begin{array}{r}-6.82 \\
(1.55)\end{array}$ & $\begin{array}{l}0.11 \\
(0.07)\end{array}$ & $\begin{array}{l}\text { Washing of } \\
\text { samples }\end{array}$ & $\triangle V_{p}$ & -5.6 & -3.0 & 3.9 & -46.6 & -51.7 & 16.1 \\
\hline
\end{tabular}

inside the sample. In the SP samples we were unable to make ultrasound measurements beyond cycle 10 , because fragments were breaking off making the surfaces uneven, thereby making it impossible to take reliable measurements. All we could observe therefore was a decline in speed up to cycle 10 . In $\mathrm{CF}$, the $V_{P}$ value remained constant until cycle 15 in which the measurements became more disparate due to the appearance of new cracks. After this cycle, as happened in SP, it was impossible to measure the ultrasounds because a large amount of material had broken off.

The $V_{P}$ value at the end of the test is shown in figure 3, and we can see that compared to the intact samples, in all the rocks except DB and AV there has been a slight fall in the ultrasound velocity value. In the cases of $\mathrm{DB}$ and $\mathrm{AV}$, the increase may be explained if we bear in mind the standard deviation of the average value for the intact samples, as the value obtained is only slightly higher.

\subsection{Resistance to salt crystallization}

The salt crystallization test was more aggressive than the freeze-thaw test, not only in terms of the loss of material it induced, but also in terms of the speed with which visible damage was inflicted on the test samples.

During the first cycles, there was an increase in the weight of the AU and SP stones due to the fact that saline solution entered the pore system (table 5). By cycle 5, fragments (splintering process, ICOMOS 2008) had begun to fall off the test samples, after which SP maintained a more or less constant mass, as did AU, although cracks began to appear in the AU samples. Some of these cracks penetrated inside the samples but in no cases did this result in loss of material (figure 5). It is important to note that these cracks developed perpendicular to the stratification plane. In addition, in both rocks, the presence of smectites may also have played a part in the decay. This is because each cycle involves submerging the samples in the solution and then drying them in a ventilated oven; this process leads to the wetting and drying of the smectites, so producing a variation in the spacing of these clays, thus increasing the fatigue suffered by the samples. In the case of CF the damage, and the resulting significant loss of material, began during cycle 3 (figure 5) and continued until cycle 5. After these cycles, we observed an increase in weight due to the fact that salts were penetrating the new cracks that had developed. CF suffered a further important loss of material around cycle 10 due to the pressure exerted by the salt when it crystallized inside these new cracks. There was a further weight increase later on caused by salt entering the new pores and cracks; and later, only a minimum amount of material was lost, and the weight remained more or less constant (table 5) until the end of the test. The damage suffered by this stone was in the form of splintering and flaking (ICOMOS 2008) on the surface and continued until the edges of the sample became rounded. One of the main causes of the serious damage suffered by this stone is directly related to the fact that it has a high percentage of pores of around $0.3 \mu \mathrm{m}\left(P_{\mathrm{I}}\right.$, table 1$)$, the pores in which the pressure caused by crystallization is most effective. In both rocks, the damage suffered was near the surface of the sample, and gradually progressed inside. According to Benavente et al (2004), the worst damage occurs in the first millimetres below the surface, due to the fact that the thenardite is deposited very near the surface. Espinosa-Marzal et al (2011) also showed that the phase change from thenardite to mirabilite allows the mirabilite to crystallize at a slightly greater depth than the thenardite (approximately the first 2 or $3 \mathrm{~mm}$ ) producing very similar damage to that observed in our samples.

The TA, DB and AV stones only experienced slight weight increases and did not suffer any visible damage (table 5). DB was hardly damaged at all due to the fact that it has a low level of porosity and because of its dolomite composition, which is less susceptible to alteration than calcite (MartinezMartinez 2008). TA resisted the attack very well due to the high compactness of the rock and its low percentage of small pores, as 'vuggy' porosity does not affect the level of damage caused by salt or ice crystallization (Benavente et al 2011). Finally, AV did not suffer damage due to the fact that the clasts are strongly cemented together. Both the clasts and the cement are composed of silicates, a material that is less prone to damage than carbonates. The behaviour of the porous system $\left(P_{I}, A_{x}\right.$ and $S$ ), discussed previously, also influenced the ability of this stone to withstand decay compared to the others.

At the end of the test, samples were washed several times in a tank with deionized water until any salt crystals that may have been inside were dissolved and eliminated. The water was changed every day and the cleaning of samples was monitored by conductivimetry. After six days the conductivity of water reached a constant background value, and we therefore considered that the stones no longer contained any salts. Due to the amount of salt retained and the specific petrological properties of the six stones, SP, AU and above all 
CF were the samples with the greatest loss of fragments due to the cracks that appeared after they were washed. By contrast TA, DB and AV did not lose any weight (table 5).

The ultrasound measurements on these samples $\left(V_{P}\right.$, table 5) have revealed certain characteristics that would have gone unnoticed if all we had studied were changes in the visual appearance and changes in weight during the salt crystallization test. In addition to suffering a slight loss of material, SP also showed a slight drop in $V_{P}$, which afterwards remained constant. Given that the loss of material was limited to the surface of the samples, the fall in the velocity of the $P$ waves was mainly due to the loss of cohesion between the clasts closest to the surface and not to the appearance of new pores or cracks inside the sample. The greatest changes in the $V_{P}$ measurement were in $\mathrm{CF}$, because new cracks appeared as the number of cycles increased, leading to a fall in velocity until by the last cycle the $V_{P}$ value had fallen to half its initial value. In the case of $\mathrm{AU}$, in the first ultrasound readings, we observed a slight increase in the $V_{P}$ value, which indicated that the pores were filling up with salts, a process which continued until the final cycles, in which sodium sulphate crystals produced important cracks that led to a fall in the $V_{P}$ values. The weakness of this rock was due to the direction of the anisotropy, which led to the appearance of cracks and to the weakness shown in the uniaxial compression test. AU is the stone with the greatest difference between $\Delta M$ and $\Delta m$, which suggests the presence of an anisotropy due to structural, textural or compositional aspects (Fort et al 2011) and may explain the growth of cracks along the preferential orientation of its clasts. The ultrasound velocity values for DB hardly changed. This was not the case for AV, which showed a significant increase in velocity at the first reading to a level at which it remained constant for the other readings. This indicates that although the pores initially filled up with salt, the strong intergranular cohesion seems to have counteracted the pressure exerted by the salt crystals and as a result there was no damage to the material. However, if some of the pores were filled with salt this could pose a problem for this rock in the long term. Lastly, the travertine from Albox (TA) behaved in a more irregular manner with $V_{P}$ values falling and rising alternately. These variations were probably due to the progressive deterioration of the fabric of the rock with salts crystallizing in the empty spaces followed by cracking and then further crystallization and filling of the pores (Ruedrich and Siegesmund 2007). In figure 3 we can see that the $V_{P}$ values at the end of the test are lower than those obtained in intact samples, a fall that was particularly notable in CF and AU. Once again, AV obtained a slightly higher value than the intact sample, although as happened in the freeze-thaw test, it is within the standard deviation for this rock.

If we rank the rocks in order of their capacity to resist damage, AV would be the most durable, although it may retain a significant amount of salt inside its pores (could be dangerous in the long term), as may TA and DB. The SP stone did not suffer such a serious loss of material as in the freeze-thaw test, because only the clasts closest to the surface broke off. The weakest stones were $\mathrm{AU}$, in which cracks appeared, and $\mathrm{CF}$, from which a significant number of small fragments broke off. They were also the stones that retained most salt.
Table 6. Colour measurements for intact (I) and altered samples after freeze-thaw (FT) and salt crystallization (Sa) tests. $\mathrm{L}^{*}$ : lightness; $\mathrm{a}^{*}$ and $\mathrm{b}^{*}$ : chromatic parameters; $\Delta E^{*}{ }_{94}$ : colour differences between intact and altered samples; $\Phi(\sigma)$ : mean value of $\mathrm{L}^{*}, \mathrm{a}^{*}, \mathrm{~b}^{*}$ of intact samples and the standard deviation is shown in brackets; FT $(\sigma)$ and $\mathrm{Sa}(\sigma)$ are the values measured in the freeze-thaw and salt test, respectively, and their standard deviation. For stone acronyms see table 1 .

\begin{tabular}{|c|c|c|c|c|c|c|c|c|c|}
\hline & & \multirow[b]{2}{*}{$\begin{array}{l}\Phi(\sigma) \\
\text { Max-min } \\
\text { FT }(\sigma) \\
\text { Sa }(\sigma)\end{array}$} & \multicolumn{2}{|c|}{$\mathrm{L}^{*}$} & \multicolumn{2}{|c|}{$a^{*}$} & \multicolumn{2}{|c|}{$\mathrm{B}^{*}$} & $\Delta E_{94}^{*}$ \\
\hline SP & I & & $\begin{array}{l}85.3 \\
91.3 \\
81.3 \\
76.8 \\
\end{array}$ & $\begin{array}{l}(4.1) \\
78.3 \\
(4.4) \\
(2.4) \\
\end{array}$ & $\begin{array}{l}3.0 \\
4.9 \\
3.4 \\
4.1 \\
\end{array}$ & $\begin{array}{l}(1.2) \\
1.3 \\
(1.2) \\
(0.8) \\
\end{array}$ & $\begin{array}{l}14.3 \\
19.4 \\
19.1 \\
19.5 \\
\end{array}$ & $\begin{array}{l}(3.3) \\
8.8 \\
(2.9) \\
(1.6) \\
\end{array}$ & $\begin{array}{l}4.9 \\
9.1 \\
\end{array}$ \\
\hline TA & I & $\begin{array}{l}\Phi(\sigma) \\
\operatorname{Max}-\min \\
\text { FT }(\sigma) \\
\operatorname{Sa}(\sigma)\end{array}$ & $\begin{array}{l}72.5 \\
77.8 \\
72.5 \\
72.4\end{array}$ & $\begin{array}{l}(6.6) \\
59.4 \\
(4.6) \\
(4.8)\end{array}$ & $\begin{array}{l}5.4 \\
7.4 \\
5.9 \\
5.9\end{array}$ & $\begin{array}{l}(1.6) \\
3.3 \\
(2.8) \\
(2.9)\end{array}$ & $\begin{array}{l}17.1 \\
25.3 \\
17.8 \\
20.5\end{array}$ & $\begin{array}{l}(4.2) \\
10.3 \\
(5.8) \\
(5.8)\end{array}$ & $\begin{array}{l}0.5 \\
1.9\end{array}$ \\
\hline DB & I & $\begin{array}{l}\Phi(\sigma) \\
\operatorname{Max}-\min \\
\text { FT }(\sigma) \\
\operatorname{Sa}(\sigma)\end{array}$ & $\begin{array}{l}74.2 \\
75.8 \\
69.9 \\
67.8 \\
\end{array}$ & $\begin{array}{l}(1.1) \\
71.6 \\
(2.1) \\
(2.5)\end{array}$ & $\begin{array}{l}2.9 \\
4.2 \\
3.5 \\
4.3 \\
\end{array}$ & $\begin{array}{l}(0.5) \\
2.3 \\
(0.8) \\
(1.0) \\
\end{array}$ & $\begin{array}{l}13.1 \\
15.3 \\
14.0 \\
16.9\end{array}$ & $\begin{array}{l}(1.2) \\
11.4 \\
(1.8) \\
(3.1) \\
\end{array}$ & $\begin{array}{l}4.4 \\
6.8 \\
\end{array}$ \\
\hline $\mathrm{CF}$ & I & $\begin{array}{l}\Phi(\sigma) \\
\operatorname{Max}-\min \\
\text { FT }(\sigma) \\
\operatorname{Sa}(\sigma)\end{array}$ & $\begin{array}{l}75.6 \\
77.0 \\
73.4 \\
74.8\end{array}$ & $\begin{array}{l}(1.1) \\
74.1 \\
(1.4) \\
(1.1)\end{array}$ & $\begin{array}{l}2.1 \\
2.3 \\
2.6 \\
2.2\end{array}$ & $\begin{array}{l}(0.1) \\
1.9 \\
(0.3) \\
(0.2)\end{array}$ & $\begin{array}{l}10.7 \\
11.8 \\
13.9 \\
11.3\end{array}$ & $\begin{array}{l}(0.7) \\
9.2 \\
(1.2) \\
(1.3)\end{array}$ & $\begin{array}{l}3.0 \\
0.9\end{array}$ \\
\hline $\mathrm{AU}$ & I & $\begin{array}{l}\Phi(\sigma) \\
\operatorname{Max}-\min \\
\text { FT }(\sigma) \\
\operatorname{Sa}(\sigma)\end{array}$ & $\begin{array}{l}61.6 \\
64.5 \\
58.1 \\
57.3\end{array}$ & $\begin{array}{l}(1.6) \\
59.9 \\
(1.0) \\
(1.6)\end{array}$ & $\begin{array}{l}3.7 \\
4.1 \\
4.0 \\
4.1\end{array}$ & $\begin{array}{l}(0.2) \\
3.4 \\
(0.2) \\
(0.6)\end{array}$ & $\begin{array}{l}16.2 \\
17.3 \\
18.9 \\
18.6\end{array}$ & $\begin{array}{l}(0.6) \\
15.2 \\
(0.8) \\
(0.6)\end{array}$ & $\begin{array}{l}3.8 \\
4.5\end{array}$ \\
\hline $\mathrm{AV}$ & I & $\begin{array}{l}\Phi(\sigma) \\
\text { Max-min } \\
\text { FT }(\sigma) \\
\operatorname{Sa}(\sigma)\end{array}$ & $\begin{array}{l}65.7 \\
68.6 \\
63.9 \\
61.5\end{array}$ & $\begin{array}{l}(2.4) \\
61.4 \\
(1.7) \\
(1.5)\end{array}$ & $\begin{array}{l}3.2 \\
5.1 \\
2.6 \\
2.8\end{array}$ & $\begin{array}{l}(0.9) \\
2.3 \\
(0.2) \\
(0.3)\end{array}$ & $\begin{array}{l}12.0 \\
16.7 \\
10.6 \\
11.7\end{array}$ & $\begin{array}{l}(2.0) \\
10.1 \\
(0.8) \\
(1.4)\end{array}$ & $\begin{array}{l}2.1 \\
4.2\end{array}$ \\
\hline
\end{tabular}

\subsection{Colour change assessment}

Table 6 shows the results obtained by spectrophotometry. We took 50 measurements to establish an average value $(\Phi)$ and a standard deviation $(\sigma)$ of the values of $L^{*}, a^{*}$ and $b^{*}$ for each rock in intact samples (I, table 6). In SP and TA we can see that the values, especially those of $L^{*}$ and $b^{*}$, vary considerably due to the heterogeneities in these rocks; in the first due to the fact that there are some areas that are yellower than others due to the presence of iron oxides while in the second this is due to the pronounced banding sometimes observed in this rock. The other varieties show a low dispersion of the values, which means that their chromaticity and lightness are very homogenous. The greater homogeneity of CF compared to SP or TA is worthy of note. We have also recorded the maximum and minimum values measured in the intact samples (table 6). The highest lightness value (91.9) was obtained in SP. However, this material varies a lot and $L^{*}$ can fall as low as 78.3, a lightness very similar to that of other rocks such as TA, DB or CF. In general, the value of the chromatic axis $a^{*}$ is low, while that of $b^{*}$ is higher with a tendency to yellowish colours (positive value of $b^{*}$ ).

Once the aging tests had been completed we measured the $L^{*}, a^{*}$ and $b^{*}$ values again in the altered samples (table 6) and calculated the difference in colour compared to the intact samples $\left(\Delta E^{*}{ }_{94}\right.$, table 6). In general, we observed that the most significant changes occurred in the salt crystallization 

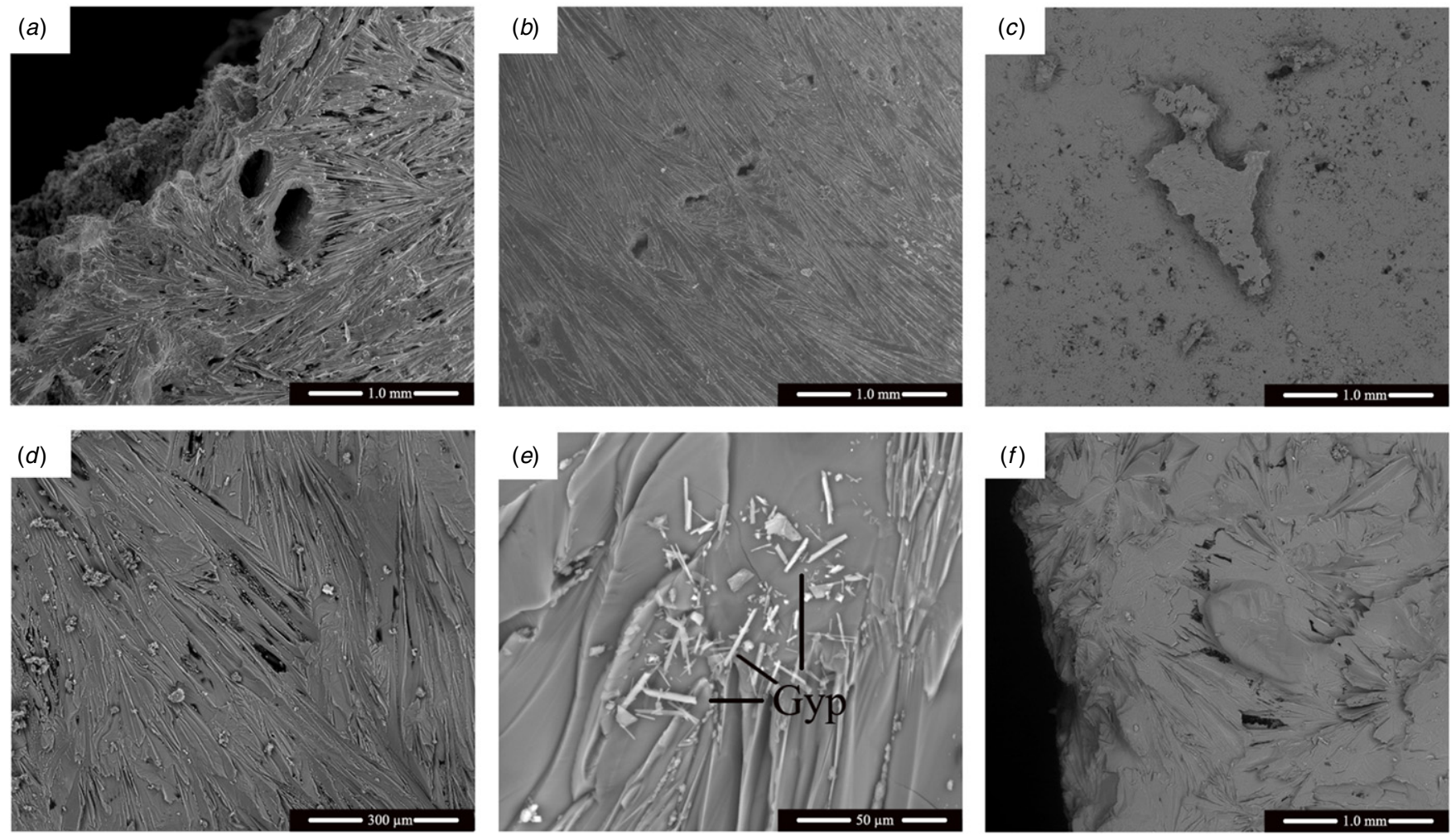

Figure 6. ESEM images of the surfaces of Santa Pudia limestone samples (a), Albox travertine $(b)$, Fraga limestone $(d)$ and Villaviciosa sandstone $(f)$ after undergoing salt crystallization aging test. Detail showing the differences in alteration between the calcite and the dolomite in Boñar dolostone $(c)$ and the formation of acicular crystals of gypsum (Gyp) on the saline crust of the Uncastillo sandstone (e).

test $(\mathrm{Sa})$, especially in the $\mathrm{SP}$ and DB samples $\left(\Delta E^{*}{ }_{94}=\right.$ 9.1 and 6.8 respectively), characterized above all by a loss of lightness. The results of the freeze-thaw test showed less dramatic changes, such that in the case of AV and above all in TA they were not appreciable $\left(\Delta E^{*} 94=2.1\right.$ and 0.5 , respectively). Nonetheless the intact samples, in some cases, have a high standard deviation for the tristimulus values, and we can therefore say that any changes that may have occurred are minimal. Only in DB and very slightly in SP and $\mathrm{AU}$, can the changes be noticed with the naked eye, a fact confirmed by the spectrophotometer measurement at the end of the salt crystallization test. In addition to a loss of lightness, the changes we observed also result in a general tendency to turn yellow.

\subsection{Microtextural analysis of stones affected by salts}

ESEM observation of fragments of about $1 \mathrm{~cm}^{3}$ that had been submitted to the salt crystallization test produced somewhat different results to those on cubic samples with $5 \mathrm{~cm}$ edges, in spite of being tested under the same conditions. The main difference was the production of a layer of thenardite on the surface of the fragments, which coated them almost completely and which was characterized by a long, dendritic, type III habit (Rodriguez-Navarro et al 2000) (figure 6). The fact that in this case the salt appeared in the form of efflorescences rather than sub-efflorescences was due to the small size of the fragments, which allowed the salts to evaporate more quickly than in the larger cubes, thereby favouring the direct precipitation of the thenardite from the supersaturated saline solution in which the samples were immersed (Rodriguez-Navarro et al 2000, Flatt 2002). The distribution of thenardite above all on the surface has reduced the damage suffered by the fragments, because the process of dehydration by which mirabilite converts to thenardite was not significant inside the rock.

In DB the thenardite crystals with dendritic habit were only found on the edges of the sample, while closer to the centre the salt was more homogenous and had no defined habit. Small 'islands' (figure 6(c)) were also formed, due to the fact that dolostone dissolved less than limestone (Martinez-Martinez 2008). Acicular crystals of gypsum developed occasionally in AU, and were identified using EDX microanalysis (figure 6(e)). The development of this phase indicates that in addition to the physical alteration produced by the pressure from salt crystallization, the samples also suffered chemical alteration, which released calcium into the solution. This calcium, together with the sulphate ions provided by the salt, led to the appearance of this saline phase.

Figure 7 shows the way the salt penetrates into the inside of the fragments, filling the pores and coating and/or corroding the surface of the crystals. In figures $7(a)$ and $(b)$ we can see that the thenardite crystals are coating the inside of the SP sample. In TA, we can also see that the saline phase has coated the grains of calcite (figure $7(c)$ ) and that long, thin sodium sulphate crystals have developed between the sparite crystals (figure $7(d)$ ). In the case of DB (figure 7(e)), we can see the incipient alteration of a calcite crystal. Using microanalysis we observed that a calcite crystal surrounded by dolomite was 

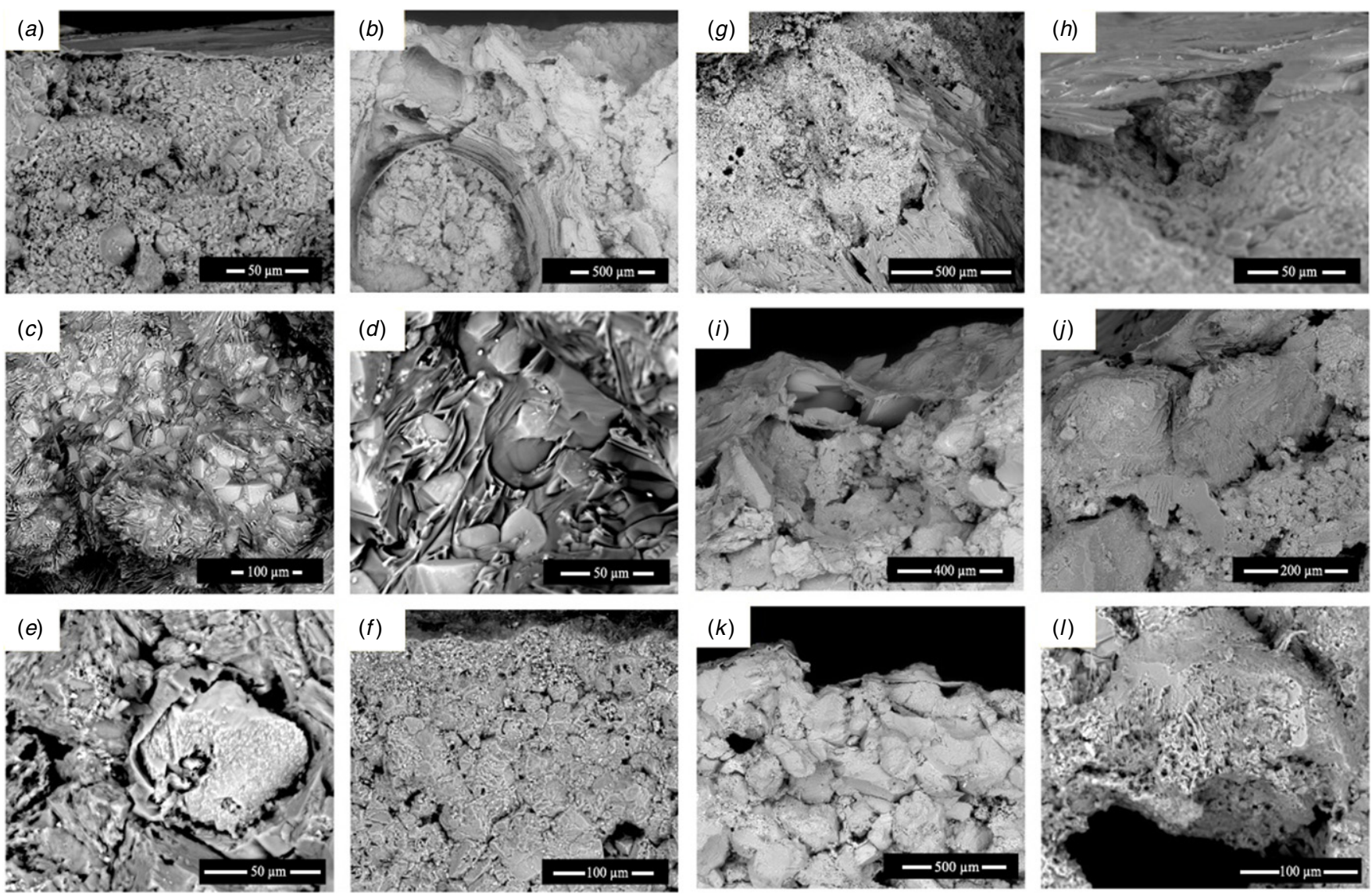

Figure 7. ESEM images of the inside of the specimens of Santa Pudia limestone $(a)$ and $(b)$, Albox travertine $(c)$ and $(d)$, Boñar dolostone $(e)$ and $(f)$, Fraga limestone $(g)$ and $(h)$, Uncastillo sandstone $(i)$ and $(j)$ and Villaviciosa sandstone $(k)$ and $(l)$ after undergoing salt crystallization aging test.

altered in a different way. In figure $7(f)$, there is a profile of the Boñar dolostone in which we can see severe alteration on the surface. Both the alteration and the salt concentration are reduced as we move inside the sample. The alteration suffered by CF was similar to that of SP but more intense, as greater corrosion and general damage could be observed on the calcite (figures $7(g)$ and $(h)$ ). The fact that AU has a mixed composition led to a difference in the alteration pattern, which was greater in the calcite than in the quartz (figures 7(i) and $(j))$. Lastly, there was almost no alteration of the quartz clasts in the AV stone, with the greatest alteration taking place in the feldspars, as detected by microanalysis (figures $7(k)$ and $(l)$ ).

\subsection{Pore system variations in stones affected by ice and salt crystallization}

We used MIP to analyse the variations in the pore system of the materials subjected to the ice and salt crystallization tests. To this end, we compared the porosity values $\left(P_{I}, P_{\mathrm{FT}}\right.$ and $P_{\text {Sa }}$, table 1) and the porosimetry curves (I, FT and Sa curves, figure 2) of intact and altered samples. In figure 2 we used the same scale, both vertically and horizontally, to compare the intact and the altered samples as well as the six rocks. As a general trend, we observed that the porosity of the altered samples $\left(P_{\mathrm{FT}}\right.$ and $\left.P_{\mathrm{Sa}}\right)$ was lower in most cases than that of the intact samples $\left(P_{I}\right)$. However, the difference was not important because it was within the standard deviation of each stone. The percentage of pores of less than $1 \mu \mathrm{m}$ was also lower in all the altered samples than in the intact samples, above all in those damaged by salt, although in most of the rocks the mean pore entry radius ( $r_{\mathrm{FT}}$ and $r_{\mathrm{Sa}}$, table 1) increased in all the ranges. This increase in the average pore size can be seen clearly in figure 2, in which it can be seen that the FT and Sa curves are shifted towards higher pore sizes than the intact ones (I).

If we analyse each stone in detail, in SP (SP, figure 2) the pore system hardly undergoes any changes as the porosity percentage and the pore size distribution are similar in intact and salt-damaged samples, the only difference being in the ice-damaged samples in which the pores of less than $1 \mu \mathrm{m}$ are more abundant. The bimodal distribution is similar for the I and FT curves, while in the Sa curve we can see that there are more pores in the ranges $0.1-1$ and $>100 \mu \mathrm{m}$ and a more pronounced peak. In addition in these two ranges we can see that the $r$ value increases in the altered samples to a greater degree than the other ranges. In the TA sample the proportion of small pores of less than $1 \mu \mathrm{m}$ fell dramatically, while that of large pores increased, due to the crystallization pressure exerted by the salt in the small pores, especially in the range $1-10 \mu \mathrm{m}$, which undergoes a significant increase in its proportion. In the freeze-thaw test, the fall in the percentage of small pores and the increase in that of large pores is less pronounced than in the salt crystallization test. In figure 2 (TA) 
we can see how in the distribution of curve I, approximately bimodal and with more pores of less than $1 \mu \mathrm{m}$, there is a shift from the small pores to the large ones $(>10 \mu \mathrm{m})$ after the samples were altered in both tests. This fact shows how crystallization both of ice and of salt has caused the pores in the intact samples to increase in size. In the DB samples, the damage produced by the ice and the salt was different. In the freeze-thaw test, the pores of less than $0.1 \mu \mathrm{m}$ increased in size towards the $0.1-1 \mu \mathrm{m}$ range. In percentage terms the increase in the number of pores within this range was from $55.5 \%$ in the intact samples to $85.6 \%$ in the altered samples. If we observe the porometric curve for $\mathrm{DB}$, we can see that it changes from the polymodal curve with no clear peaks for the intact samples to another curve with a maximum more defined peak around $0.48 \mu \mathrm{m}$ in the samples damaged by ice. Something similar occurred in the salt crystallization test but instead of the increase in size being concentrated in the 0.1$1 \mu \mathrm{m}$ range, there was also a significant number in the $1-10 \mu \mathrm{m}$ range, possibly because this test is more aggressive than the freeze-thaw test. In CF, in spite of the serious decay observed in both aging tests, the porous system hardly changed. This can be seen both in table 1 and in figure 2, as the porometric distribution for the altered samples is almost the same as that for the intact samples. In the case of the salt crystallization test, the damage was concentrated above all on the surface of the samples. As a result, when we analysed the samples with MIP, we could not analyse the surface only, because it broke up too easily, obliging us to analyse parts of the rock below the surface that were more intact. Around $1 \mu \mathrm{m}$ however there was a slight broadening of the curve for the salt-damaged samples, caused by the appearance of new fissures which definitely affected the inner parts of the sample. In the case of AU, in both tests, freeze-thaw and salt crystallization, the porometric curve shifted towards larger pores. In the freeze-thaw test, almost $70 \%$ of the pores were concentrated in the $10-100 \mu \mathrm{m}$ range. In the salt crystallization test, a large percentage of the total number of pores fell within this range, but it is also interesting to note that the average radius of the pores greater than $100 \mu \mathrm{m}$ has increased considerably, from approximately $143 \mu \mathrm{m}$ in the intact samples to $227 \mu \mathrm{m}$ in the samples altered by the salt crystallization test. This could be due to the appearance of cracks, which then gave rise to the substantial loss of mass recorded in the test (table 5). Lastly, AV followed the general tendency of the increase in the average size of the pore in each range and a general reduction in the percentage of small pores in favour of larger ones. Both the values in table 1 and the curves in figure 2 show that this stone is very resistant to decay, and that the values for the intact samples hardly changed. Figure 2 also shows that the peak where the majority of the pores are concentrated has become thinner and higher compared to the intact samples.

The differences between the curves for the altered and the intact samples are probably due to new cracks appearing and the broadening by dissolution of pre-existing pores inside the rocks (Angeli et al 2008). This was the change in the porous system detected by the ultrasounds as the subsequent readings indicated the degree of damage that the rock was suffering. For example, in the AV samples whose weight and ultrasound velocity hardly changed, the curves for the intact and the altered samples were very similar. Or in the case of TA and $\mathrm{DB}$, in which the $V_{p}$ readings showed a constant decay in the system, this resulted in a shift from small pores to larger ones, making clear that the positive variations in $V_{p}$ were due to the new empty spaces created being filled with salt. In CF, we can see that most of the damage occurred on the surface, as its porous system remained almost unchanged. In later cycles the appearance of new cracks towards the inside caused a loss of material and the resulting fall in $V_{p}$ we recorded. The same happened with SP, in which the greatest damage was the loss of the clasts closest to the surface. Lastly, in AU the appearance of large pores was probably due to the emergence of large cracks in the salt crystallization test.

\section{Conclusions}

On the basis of our results, we have evaluated the quality of the different rocks we studied:

The Santa Pudia limestone (SP) and the Fraga limestone (CF) have the highest percentage of porosity of the six varieties of rock we studied. In SP the porometric distribution is bimodal due to skeletal remains of different organisms and the interclastic pores, whereas in $\mathrm{CF}$ the pores are concentrated around $0.4 \mu \mathrm{m}$ (unimodal distribution). Both varieties have a high saturation coefficient and the porous system is well connected. In spite of their high level of porosity, they achieved ultrasound wave propagation velocities of $3200-3600 \mathrm{~m} \mathrm{~s}^{-1}$, which puts them in the mid range between those of the other rocks. This velocity was slightly lower in CF due to the fact that it contained more organic matter. In addition, the anisotropy coefficients showed that SP and CF are less texturally homogeneous than the other rocks, due to a higher value and a greater difference between the relative and the total anisotropy coefficient. The Albox travertine (TA) and the Boñar dolostone (DB), by contrast, have the lowest porosity. The porous system in DB however is better connected than that of TA, which gives it a high saturation coefficient. The porometric curve of the intact rocks has a slightly heterogeneous distribution in that there is no dominant pore size. As these are the most crystalline and least porous rocks, they had the highest wave propagation velocities, the highest dynamic elastic modules, and their anisotropy coefficients show that they are the most homogeneous rocks we studied. The Uncastillo (AU) and Villaviciosa (AV) sandstones had very similar porosity values and a unimodal porometric distribution. The porous system of $\mathrm{AV}$ is not as well connected as that of AU and therefore has a lower saturation coefficient. The mineralogical composition of the samples influenced the ultrasound velocity, in which AV obtained the lowest score. Nonetheless, the anisotropy coefficients of AV are more homogeneous, and AU has the highest total anisotropy coefficient. SP, CF and AU may not stand the test of time due to the high porosity value and the high anisotropy detected by the ultrasounds, especially if they are oriented in the same direction as said anisotropy.

The uniaxial compression test showed that DB is the most resistant stone. This is due to its small pore size, its low porosity and its dolomite composition. By contrast, the rocks with the 
highest porosity, CF and SP, obtained the lowest scores for compressive strength. AU had a lower compressive strength value than expected.

The stones that proved most resistant to the freeze-thaw test were TA, DB, AU and AV. SP and CF however suffered continuous loss of material, and this got worse in the final cycles. The loss of material in SP was due to the fact that poorly cemented clasts broke off, while in CF it was due to the loss of fragments, caused by the cracking and eventual fracturing of the test samples. The saturation coefficient and the degree of interconnection between the pores played fundamental roles in the decay processes in $\mathrm{SP}$ and $\mathrm{CF}$, as the damage produced by the ice is particularly severe in rocks with well-connected pores and high saturation. In addition and in spite of its high degree of saturation and the good interconnection between its pores, the low porosity of DB and its high degree of compactness enabled this rock to endure the test without being damaged.

In the test measuring resistance to salt crystallization, $\mathrm{CF}$ suffered the greatest loss of material due to flaking, due to its high concentration of pores between 0.1 and $1 \mu \mathrm{m}$. For SP this test was less aggressive than the freeze-thaw test, because as it has large pores, only minimal damage was caused by salt crystallization inside the sample. In both samples the damage occurred above all on the surface, and later progressed inwards. This damage is linked essentially to the crystallization characteristics of the sodium sulphate, which tends to occur at or close to the surface. In AU, cracks appeared almost perpendicular to the stratification plane, although these did not cause any loss of material. There were no apparent alterations to the other rocks or changes in weight at the end of the test, due both to their hydric behaviour, especially in TA, and to their mineral composition especially in DB and AV.

The presence of smectites amongst the clay minerals in SP and $\mathrm{AU}$ caused their resistance to alteration to wane towards the end of the aging tests. This was more evident in SP.

There was no change in the colour of the samples used in the two accelerated aging tests compared to the intact samples, and all we detected was a general loss of lightness and a slight tendency to turn yellow. The only notable change was in the DB samples used in the salt crystallization test.

ESEM observation showed that the salts were coating and chemically attacking the calcite crystals, occasionally causing gypsum to form. However the damage to the samples used for observation under ESEM was different from the damage suffered by the $5 \mathrm{~cm}$ edge samples, mainly because smaller samples were used in ESEM. Mercury injection porosimetry analysis of the samples altered by the freeze-thaw and salt crystallization tests showed that in the porous systems there was a general tendency to an increase in the average pore size in all the ranges and a fall in the percentage of small pores. The difference in the porometric curves between the intact and the altered samples suggests that new cracks have appeared and there has been an increase in the size of pre-existing pores. In $\mathrm{SP}$ and $\mathrm{CF}$, in spite of the damage suffered during the aging tests, the porous systems remain very similar to those of the intact samples. This shows that above all the damage affected the surface of the samples and only towards the end of the tests did it begin to affect the inside. In samples TA and DB, the general tendency continued and the curves shifted from a heterogeneous distribution to a unimodal or bimodal one. In $\mathrm{AU}$, the freeze-thaw test favoured the concentration of pores of between 10 and $100 \mu \mathrm{m}$; while in the salt crystallization test, the large pores $(>100 \mu \mathrm{m})$ dominated. This confirms the idea that the notable increase in pore size was related to the appearance of cracks, especially at the end of the test. The AV samples showed a very similar distribution in intact and altered samples. This rock is very resistant to decay and as a result its porous system was hardly affected by the tests. Finally, the ultrasound measurements taken during the aging tests are in line with the observations we made with porosimetry, namely that both the negative and positive variations in the $V_{p}$ value that took place during the tests were due to new cracks opening up and the new spaces they formed being filled. In some samples such as AV whose porous system has hardly changed, the velocity remained constant; however, in the samples with the greatest alteration, SP, CF and AU, the measurements varied more. In the case of TA and DB, these variations were clearly associated with the shift from small to larger pores.

In short, DB performed best in the accelerated aging tests, in addition to having homogenous dynamic elastic properties and a higher compressive strength value. At the other end of the scale, SP, CF and AU behaved worst, as they suffered more severe damage from ice and soluble salt crystallization inside the samples, due to their petrophysical characteristics, and in particular the behaviour of their porous systems and their anisotropies. TA stood out for its high compactness, as shown by its high compressive strength and the coefficients obtained with ultrasounds, and its durability against decay. The good performance of AV was due mainly to the siliceous composition of both its clasts and its cement, which make it very resistant to decay.

\section{Acknowledgments}

This study was financially supported by Research Group RNM179 of the Junta de Andalucía and by Research Project P09-RNM-4905. We are grateful to Nigel Walkington for his assistance in translating the original text.

\section{References}

Anania L, Badala A, Barone G, Belfiore C M, Calabro C, La Russa M F, Mazzoleni P and Pezzino A 2012 The stones in monumental masonry buildings of the Val di Noto area: new data on the relationships between petrographic characters and physical-mechanical properties Constr. Build. Mater. 33 122-32

Andriani G F and Walsh N 2002 Physical properties and textural parameters of calcarenitic rocks: qualitative and quantitative evaluations Eng. Geol. 67 5-15

Angeli M, Benavente D, Bigas J P, Menendez B, Herbert R and David C 2008 Modification of the porous network by salt crystallization in experimental weathered sedimentary stones Mater. Struct. 41 1091-108

Angeli M, Bigas J P, Menendez B, Herbert R and David C 2006 Influence of Capillary Properties and Evaporation on Salt Weathering of Sedimentary Rocks Heritage (Madrid: Weathering and Conservation Balkema Publishers) pp 253-9 
ASTM 2005 Standard method for laboratory determination of pulse velocities and ultrasonic elastic constants of rock ASTM D2845-05

Bell F G 1993 Durability of carbonate rock as building stone with comments on its preservation Environ. Geol. 21 187-200

Benavente D 2002 Modelización y estimación de la durabilidad de materiales pétreos porosos frente a la cristalizacion de sales $P h D$ Thesis University of Alicante

Benavente D 2011 Why pore size is important in the deterioration of porous stones used in the built heritage Macla 15 41-2

Benavente D, Garcia del Cura M A, Fort R and Ordoñez S 2004 Durability estimation of porous building stone from pore structure and strength Eng. Geol. 74 113-27

Benavente D, Garcia del Cura M A, Garcia-Guinea J, Sanchez-Moral S and Ordoñez S 2004 Role of pore structure in salt crystallization in unsatured porous stone J. Cryst. Growth. $260534-44$

Benavente D, Sanchez-Moral S, Fernandez-Cortes A, Cañavera J C, Elez J and Saiz-Jimenez C 2011 Salt damage and microclimate in the Postumius Tomb, Roman necropolis of Carmona, Spain Environ. Earth. Sci. 63 1529-43

Brocher T M 2005 Empirical relations between elastic wavespeeds and density in the Earth's crust Bull. Seismol. Am. 95 2081-92

Bruton G 1955 Vapour glycolation Am Mineral. 40 124-6

Buj-Fandos O 2008 Caracterización tecnológica de las rocas aragonesas de usos constructivos: propiedades hídricas y durabilidad de las rocas con uso ornamental PhD Thesis University of Saragossa

Buj O and Gisbert J 2007 Petrophysical characterization of three commercial varieties of Miocene sandstones from the Ebro valley Mater. Constr. 57 63-74

Buj O, López P and Gisbert J 2010 Characterization of pore system and their influence on decay rates caused by salt weathering on limestones and dolostones quarried in Abanto (Zaragoza, Spain) Mater. Constr. 60 99-114

Carmichel R S (ed) 1989 Practical Handbook of Physical Properties of Rocks and Minerals (Boca Raton, FL: CRC Press) p 741

Chen T C, Yeung M R and Mori N 2004 Effect of water saturation on deterioration of welded tuff due to freeze-thaw action Cold Reg. Sci. Technol. 38 127-36

Christensen N I 1996 Poisson's ratio and crustal seismology J. Geophys. Res. $1013139-56$

Colas E, mertz J D, Thomachot-Chneider C, Barbin V and Rassineux F 2011 Influence of the clay coating properties on the dilation behaviour of sandstones Appl. Clay Sci. 52 245-52

Cultrone G, de la Torre M J, Sebastian E and Cazalla O 2003 Evaluación de la durabilidad de ladrillos mediante técnicas destructivas (TD) y no-destructivas (TND) Mater. Constr. 53 41-59

Cultrone G, Sebastian E and Ortega Huertas M 2007 Durability of masonry systems: a laboratory study Constr. Build. Mater. 21 40-51

Cultrone G, Sidraba I and Sebastian E 2005 Mineralogical and physical characterization of the bricks used in the construction of the 'Triangul Bastion', Riga (Latvia) Appl. Clay Sci. 28 297-308

De Belie N, Lenehan J J, Braam C R, Svennerstedt B, Richardson M and Sonck B 2000b Durability of building materials and components in the agricultural environment, part III: concrete structures J. Agr. Eng. Res. 76 3-16

De Belie N, Sonck B, Braam C R, Lenehan J J, Svennerstedt B and Richardson M 2000a Durability of building materials and components in the agricultural environment, part II: metal structures J. Agr. Eng. Res. 75 333-47

Delgado Rodrigues J 2001 Swelling behaviour of stones and its interest in conservation. An appraisal Mater. Constr. 51 183-95

Dunham R J 1962 Classification of carbonate rocks according to depositional texture Classification of Carbonate Rocks
(American Association of Petroleum Geologists Memoir) ed W E Ham pp 108-121

Espinosa R M, Franke L and Deckelmann G 2008 Model for the mechanical stress due to the salt crystallization in porous materials Constr. Build. Mater. 22 1350-67

Espinosa R M, Hamilton A, McNall M, Whiteker K and Scherer G W 2011 The chemomechanics of crystallization during rewetting of limestone impregnated with sodium sulfate J. Mater. Res. 26 1472-81

Everett D M 1961 The thermodynamics of frost damage to porous solids Trans. Faraday Soc. 57 2205-11

Flatt R J 2002 Salt damage in porous materials: how high supersaturations are generated J. Cryst. Growth 242 435-54

Fort R 2008 La Piedra Natural y el Patrimonio construido: un mismo campo de investigación Mater. Constr. 58 289-90

Fort R, Alvarez de Buergo M, Perez-Monserrat E and Varas M J 2010a Characterization of monzogranitic batholiths as a supply source for heritage construction in the northwest of Madrid Eng. Geol. 115 149-57

Fort R, Alvarez de Buergo M, Varas-Muriel M J and Gomez-Heras M 2010b Anisotropy indices and the effects on the hydric behaviour of natural stone Geophys. Res. Abstr. 12 6830-1

Fort R, Varas M J, Alvarez de Buergo M and Martin-Freire D 2011 Determination of anisotropy to enhance the durability of natural stone J. Geophys. Eng. 8 S132-44

Garcia del Cura M A, La Iglesia A, Benavente D, Bernabeu A and Gonzalez Martin J A 2007 Mineralogía de los travertinos pleistocenos de Albox (Almería), importante recurso de materia prima de rocas ornamentales Macla 789

Gomez Fernandez F, Méndez Cecilia A J and Bahamonde J R 2003 La Formación Boñar (Cretácico Superior; norte de León): estratigrafía, geoquímica y potencial productor de roca ornamental Rev. Soc. Geol. España 16 61-72

Gonzalez de Vallejo L I, Ferrer M, Ortuño L and Oteo C 2002 Ingeniería Geológica ed (Madrid: Pearson Education) p 744

Gonzalez García F and Sanchez Camazano M 1968 Differentiation of kaolinite from chlorite by treatment with dimethylsulphoxide Clay Miner. 7 447-50

Grossi C M, Brimblecombe P and Harris I 2007 Predicting long term freeze-thaw risks on Europe built heritage and archaeological sites in a changing climate Sci. Total Environ. $377273-81$

Guydader J and Denis A 1986 Propagation des ondes dans les roches anisotropes sous contrainte évaluation de la qualité des schistes ardoisiers B. Eng. Geol. 33 49-55

Herrera L K, Arroyave C, Guiamet P, Gómez de Saravia S and Videla H 2004 Biodeterioration of peridotite and other constructional materials in a building of the Colombian cultural heritage Int. Biodeterioration Biodegradation 54 135-41

ICOMOS 2008 ICOMOS-ISCS: Illustrated glossary on stone deterioration patterns, France $78 \mathrm{pp}$

Ji S, Wang Q and Salisbury M H 2009 Composition and tectonic evolution of the Chinese continental crust constrained by Poisson's ratio Tectonophysics $\mathbf{4 6 3}$ 15-30

King M S 2002 Elastic wave propagation in and permeability for rocks with multiple parallel fractures Int. J. Rock. Mech. Min. Sci. 39 1033-43

Laycock E A 2002 Ten years of frost testing at Sheffield Hallam University Constr. Build. Mater. 16 195-205

Lewry A J and Crewdson L F E 1994 Approaches to testing the durability of materials used in the construction and maintenance of buildings Constr. Build. Mater. 8 211-22

Ludovico-Marques M and Chastre C 2012 Effect of salt crystallization aging on the compressive behaviour of sandstone blocks in historical buildings Eng. Fail. Anal. 26 247-57

Luque A, Cultrone G, Mosch S, Siegesmund S, Sebastián E and Leiss B 2010 Anisotropic behaviour of White Macael marble used in the Alhambra of Granada (Spain): the role of 
thermohydric expansion in stone durability Eng. Geol. 115 209-16

Luque A, Cultrone G, Sebastian E and Cazalla O 2008 Effectiveness of stone treatments in enhancing the durability of bioclastic calcarenite (Granada, Spain) Mater. Constr. 58 115-28

Maage M 1984 Frost resistance and pore size distribution in bricks Mater. Struct. 17 345-50

Marini P and Bellopede R 2010 The mechanical resistance of saturated stones in Glob. Stone Congr.

Martin J D 2004 XPowder, a software package for powder X-ray diffraction analysis Lgl. Dep. GR 1001/04

Martinez-Martinez J 2008 Influencia de la alteración sobre las propiedades mecánicas de calizas, dolomías y mármoles. Evaluación mediante estimadores no destructivos (Ultrasonidos) PhD Thesis University of Alicante

Martinez-Martinez J, Benavente D and Garcia del Cura M A 2011 Spatial attenuation: the most sensitive ultrasonic parameter for detecting petrographic features and decay processes in carbonate rocks Eng. Geol. 119 84-95

Molina E, Cultrone G, Sebastian E, Alonso F J, Carrizo L, Gisbert J and Buj O 2011 The pore system of sedimentary rocks as a key factor in the durability of building materials Eng. Geol. 118 110-121

Moore D M and Reynolds R C 1989 X-Ray Diffraction and the Identification and Analysis of Clay Minerals (Oxford: Oxford University Press) p 322

Mutlutürl M, Altindag R and Türk G 2004 A decay function model for the integrity loss of rock when subjected to recurrent cycles of freezing-thawing and heating-cooling Int. J. Rock. Mech. Min. 41 237-44

Ordoñez S, Fort R and Garcia del Cura M A 1997 Pore size distribution and the durability of a porous limestone Q.J. Eng. Geol. 30 221-30

Peris Mora E 2007 Life cycle, sustainability and the transcendent quality of building materials Build. Environ. 42 1329-34

Rancan A 2002 La protezione per la conservazione del patrimonio storico artistico e monumentale Notiziario Tecnico no 5 'Cultura e Tecnologia del Restauro' 127 pp

Richardson B A 1991 The durability of porous stones. Stone Industries December 26 22-5

RILEM 1980 Recommended test to measure the deterioration of stone and to assess the differences of treatment methods Mater. Struct. 13 175-253

Rodriguez Navarro C 1994 Causas y mecanismos de alteración de los materiales calcáreos de las catedrales de Granada y Jaén PhD Thesis University of Granada

Rodriguez Navarro C and Doehne E 1999 Salt weathering: influence of evaporation rate, supersaturation and crystallization pattern Earth Surf. Process. Landf. 24 191-209

Rodriguez Navarro C, Doehne E and Sebastián E 2000 How does sodium sulfate crystallize? Implications for the decay and testing of building materials Cement Concr. Res. 30 1527-34

Ruedrich J and Siegesmund S 2007 Salt and ice crystallization in porous sandstones Environ. Geol. 52 225-49

Scherer G W 1999 Crystallization in pores Cement Concr. Res. 29 1347-58

Sebastian E, Cultrone G, Benavente D, Linares Fernandez L, Elert K and Rodriguez-Navarro C 2008 Swelling damage in clay-rich sandstones used in the church of San Mateo in Tarifa (Spain) J. Cult. Herit. 9 66-76

Siegesmund S, Ullermeyer K, Weiss T and Tschegg E K 2000 Physical weathering of marbles caused by anisotropic thermal expansion Int. J. Earth Sci. 89 170-82

Simmons G 1965 Ultrason. Geol. Proc. Inst. Electron. Eng. 53 129-33

Steiger M 2005 Crystal growth in porous materials. I: the crystallization pressure of large crystals J. Cryst. Growth. 282 455-69

Suarez del Rio L M, Calleja L, Diez Sarria I, Ruiz de Argandoña V G, Rodriguez Rey A and Alonso F J 2002 Características tecnológicas de las rocas ornamentales de Asturias Trabajos de Geología 23 73-84

Török Á and Vásárhelyi B 2010 The influence of fabric and water content on selected rock mechanical parameters of travertine, examples from Hungary Eng. Geol. $115237-45$

UNE-EN 123702001 Métodos de ensayo para piedra natural. Determinación de la resistencia a la cristalización de sales (Madrid: AENOR)

UNE-EN 123712003 Métodos de ensayo para piedra natural. Determinación de la resistencia a la heladicidad (Madrid: AENOR)

UNE-EN 158862011 Métodos de ensayo. Medición del color de superficies (Madrid: AENOR)

UNE-EN 19261999 Métodos de ensayo para piedra natural. Determinación de la resistencia a lacompresión uniaxial (Madrid: AENOR)

Urosevic M 2011 Physico-chemical decay of carbonate stones: the role of atmospheric aerosols and dissolution processes PhD Thesis University of Granada

Varas M J, Alvarez de Buergo M and Fort R 2005 Natural cement as the precursor of Portland cement: methodology for its identification Cement Concr. Res. 35 2055-65

Vazquez P, Alonso J, Carrizo L, Molina E, Cultrone G, Blanco M and Zamora I 2013 Evaluation of the petrophysical properties of sedimentary buildings stones in order to establish quality criteria Constr. Build. Mater. 41 868-78

Yavuz H, Altindag R, Sarac S, Ugur I and Sengun N 2006 Estimating the index properties of deteriorated carbonate rocks due to freeze-thaw and thermal shock weathering Int. J. Rock. Mech. Min. 43 767-75 